\title{
Ulnar fractures and ligament injuries of the wrist
}

\section{Maria Moloney}





\title{
Ulnar fractures and ligament injuries of the wrist
}

\author{
Maria Moloney
}

\author{
Division of Surgery, Orthopedics and Oncology \\ Department of Biomedical and Clinical Sciences \\ Faculty of Health Science \\ Linköping University, SE-581 83 Linköping, Sweden
}

Linköping 2022 


\section{Supervisor}

Lars Adolfsson, MD, PhD, Professor

Department of Orthopaedic Surgery

Department of Biomedical and Clinical Sciences

Linköping University, Linköping

\section{Co-Supervisor}

Simon Farnebo, MD, PhD, Professor

Department of Hand Surgery, Plastic Surgery and Burns

Department of Biomedical and Clinical Sciences

Linköping University, Linköping

\section{Faculty opponent}

Niels Schep, MD, PhD, MSc

Department of Surgery

University of Amsterdam, Amsterdam, the Netherlands

\section{Examination board}

Charlotta Dabrosin, MD, PhD, Professor

Department of Biomedical and Clinical Sciences

Linköping University, Linköping

Olof Wolf, MD, PhD, Ass. Professor

Department of Orthopaedic Surgery

Department of Surgical Science, Orthopaedics

Uppsala University, Uppsala

Anders Kalén, MD, PhD, Ass. Professor

Department of Orthopaedic Surgery

Department of Biomedical and Clinical Sciences

Linköping University, Linköping 
The known is finite, the unknown infinite;

intellectually we stand on an islet in the midst of an illimitable ocean of inexplicability. Our business in every generation is to reclaim a little more land, to add something to the extent and the solidity of our possessions.

THOMAS HUXLEY 


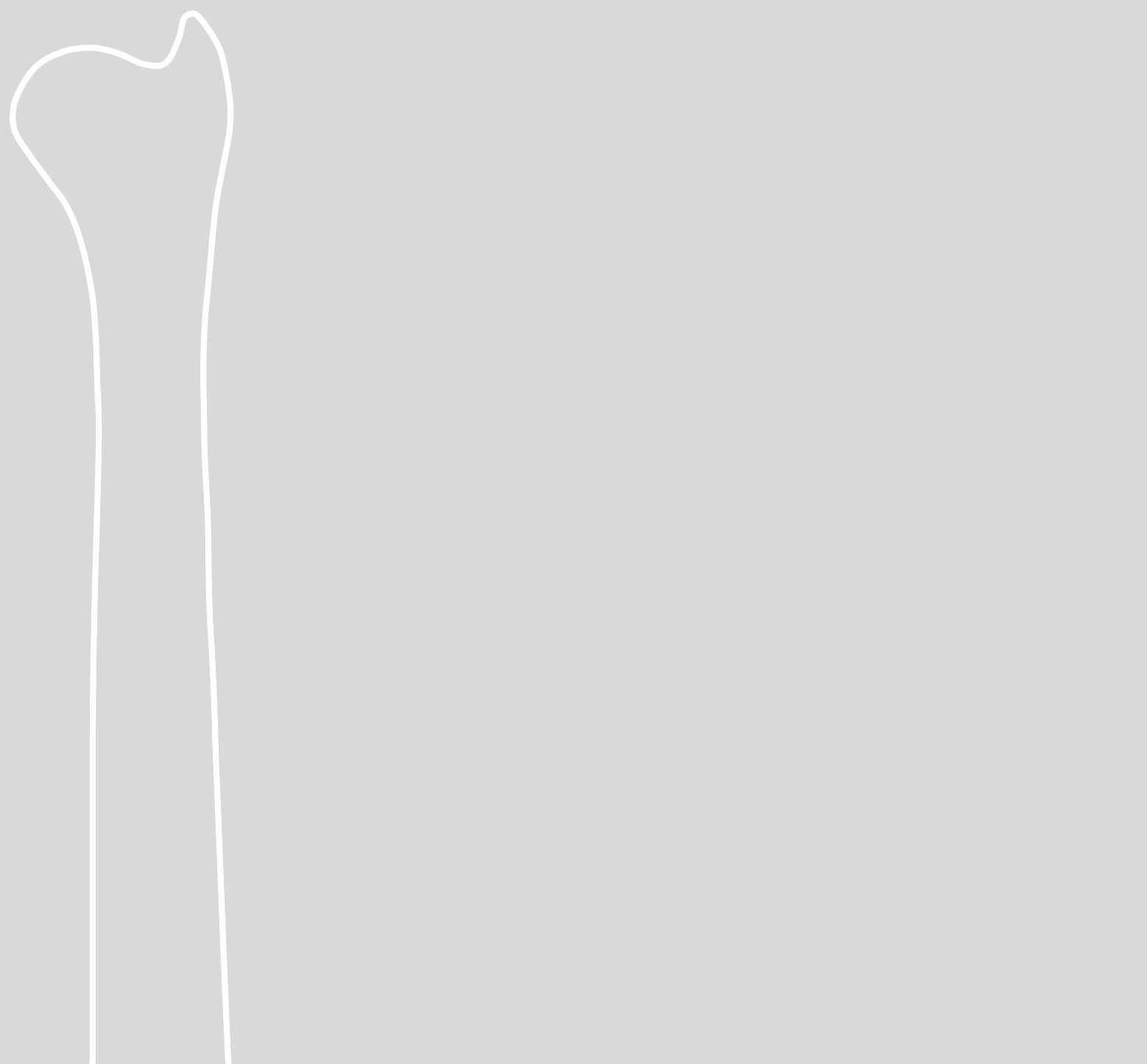




\section{Abstract}

Falling over on an outstretched hand with the wrist extended is a common accident that can cause a multitude of injuries in the wrist. Research has mainly focused on distal radius fractures while injuries of the distal ulna and adjacent ligaments have taken a back seat. If not treated adequately, these injuries may result in ulnar-sided wrist pain, sometimes referred to as the "black box" of hand surgery. The distal radioulnar joint (DRUJ) enables forearm rotation where the radio-carpal unit rotates around the fixed ulna, stabilised most importantly by the triangular fibrocartilage complex (TFCC). Painless rotation and stability of the forearm under load is important for upper limb function. If full function is to be restored after wrist injury, it is important to treat not only injury to the radius but also those to the ulna and TFCC.

The aims of this thesis were to evaluate the long-term results of TFCC injury repair, and contribute to our knowledge on fractures of the distal ulna, their epidemiology, radiographic classification and results of treatment.

The long-term outcome of 47 patients with a foveal TFCC tear was evaluated by patient-rated wrist evaluation (PRWE) and radiography 20 years after open repair. The median PRWE score was 22.6 (7-48.5), and $34 \%$ had had further surgery after the initial repair, half of these due to recurrence of DRUJ instability. Signs of osteoarthritis were seen in the radiocarpal joint in $17.5 \%$ and in the DRUJ in $34 \%$. Higher PRWE scores were seen in patients with osteoarthritis or those who had undergone further surgery. Radio-carpal osteoarthritis was less frequently seen in patients who had undergone initial arthroscopy. This study highlights the importance of arthroscopy in identifying associated injuries. Twenty years after foveal TFCC tear repair patient reported outcomes were similar to those of distal radius fractures.

Apart from fractures of the styloid process, distal ulna fractures are rare. All distal ulna fractures in the county of Östergötland 2010-2012 were identified. A total of 766 fractures were found (incidence 74/100 000 person-years), the majority of which were fractures of the ulnar styloid process (79\%) usually caused by a fall from standing height. Most patients were female (76\%), mean age at the time of injury was 63 years and $92 \%$ had a concomitant distal radius fracture. Second after styloid fractures were fractures of the ulnar neck. A retrospective study of 96 patients with 97 fractures of the distal ulna (excluding the styloid) showed that $40 \%$ were treated by internal fixation. The median PRWE score was 15 , with significantly worse scores in patients with an internally fixed distal ulna fracture compared to patients not operated. When classifying these fractures according to AO/OTA 2018, transverse extra-articular fractures (2U3A2.3) had a significantly better outcome when not treated surgically, and these probably do not require internal fixation if the distal radius provides stability and alignment.

All 97 fractures were classified by three independent observers according to three classification systems: Biyani, AO/OTA 2007, and AO/OTA 2018. Classification was repeated after a minimum of 3 weeks. Reliability and reproducibility were calculated. The reliability was judged as fair for AO/OTA 2007, and moderate for Biyani 
and AO/OTA 2018. The reproducibility was moderate for all three systems. These results together with the observers' opinions that Biyani is an easier system to use and that standard radiographs are not always sufficient for classification, leads us to conclude that a slightly modified Biyani-system together with improved radiological techniques that provide more information about the fracture pattern, may well improve accuracy, reliability and reproducibility.

A better classification of distal ulna fractures could help us in the evaluation of new and existing treatments as well as providing the information necessary for designing a treatment algorithm. After careful consideration, internal fixation is probably the treatment of choice for certain types of fracture, but this needs further investigation. 


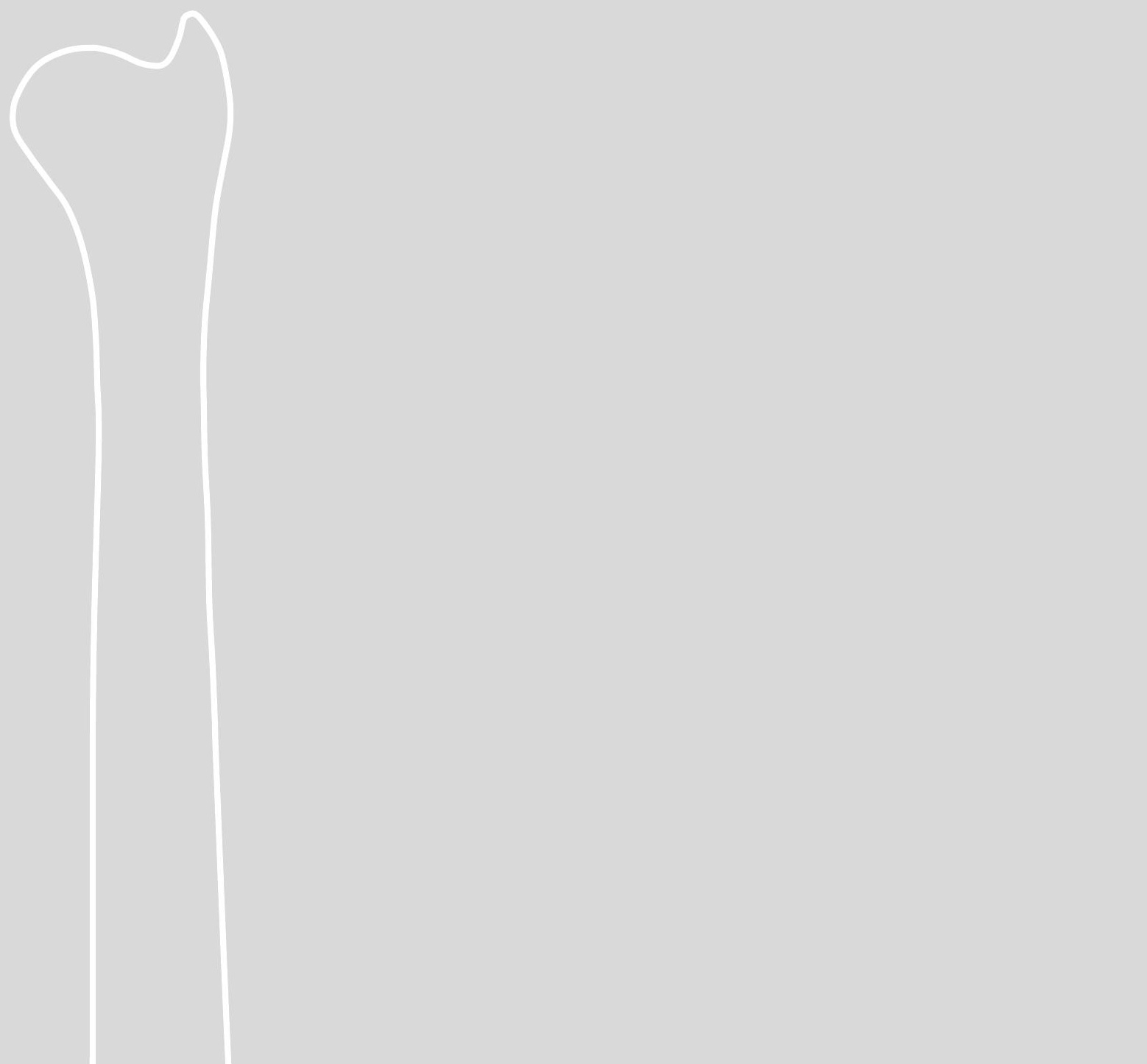




\section{Sammanfattning på svenska}

Att ramla och ta emot sig med en utsträckt hand är en vanlig olycka som kan orsaka en mängd olika skador i handleden. Medan mycket fokus har legat på benbrott på nedre delen av strålbenet (radius) har intresset varit betydligt mindre för skador på nedre delen av armbågsbenet (ulna) och närliggande ligament. Skador på denna sida av handleden kan, om de inte behandlas rätt, resultera i s.k. ulnar handledssmärta. Denna kallas ibland för handkirurgins "svarta låda" pga. den stora mängd potentiella orsaker. Rotation av underarmen kräver att leden mellan nedre delen av radius och ulna, DRUJ, fungerar adekvat så att radius och mellanhanden kan rotera runt den stabila ulna. De två underarmsbenen stabiliseras under denna rörelse framför allt av det triangulära ligamentkomplexet, TFCC. Smärtfri rotation och stabilitet i handleden vid belastning är viktigt för hela armens funktion. För att återskapa dessa förhållanden efter en skada är det viktigt att noggrant diagnosticera och behandla skador på både radius, ulna och TFCC.

Syftet med denna avhandling var att utvärdera långtidsresultatet av opererade TFCC-skador och bidra med mer kunskap om frakturer i nedre delen av ulna; hur vanliga är de, hur ska de behandlas och kan röntgenologiska klassifikationer vara till någon nytta?

I delarbete I utvärderades långtidsresultatet hos 47 patienter med en total TFCC-skada och medföljande instabilitet 20 år efter att de genomgått en kirurgisk reparation. Med hjälp av självskattningsinstrumentet PRWE, och nya röntgenundersökningar utvärderades hur patienterna upplevde funktion, smärta samt om de utvecklat artros. Patienterna upplevde funktion och smärta i den opererade handleden ungefär likt patienter som brutit handleden. En tredjedel hade behövt ytterligare kirurgi i handleden senare, men bara hälften av dessa pga. återkomst av instabilitet. Artrostecken sågs hos $17.5 \%$ i leden mellan radius och handlovsbenen och hos 34 \% i DRUJ. Patienter som utvecklat artros eller som genomgått ytterligare kirurgi hade ett sämre resultat. De patienter som genomgått en diagnostisk titthålsoperation som en del av den initiala operationen hade mer sällan utvecklat artros. Denna studie belyser vikten av titthålsoperationer för att kunna identifiera associerade skador så att man kan behandla alla skador adekvat från första början för att undvika att de leder till artrosutveckling samt att patienter som genomgått en reparation av TFCC har ett långtidsresultat jämförbart med efter de mer vanligt förkommande radiusfrakturerna.

Frakturer på nedre delen av ulna är relativt ovanliga. I delarbete II identifierades alla frakturer på nedre delen av ulna i Östergötland under åren 20102012. Under dessa år diagnosticerades 766 frakturer, vilket genererade en relativ förekomst på 74/100 000 person-år. Vanligast var frakturer i ulnas spetsiga utskott (styloiden, 79\%) och den vanligaste skademekanismen var fall i samma plan där patienten tog emot sig med en utsträckt hand. Majoriteten av patienterna var kvinnor (76\%) och medelåldern vid skadetillfället var 63 år. $92 \%$ hade samtidigt en fraktur i nedre delen av radius. Näst efter styloidfrakturer var tvärfrakturer genom ulnas hals vanligast. 
När vi i delarbete III utvärderade resultatet hos 96 patienter med 97 ulnafrakturer (ej i styloiden) hade $\mathbf{4 0} \%$ behandlats genom en operation. Patienterna upplevde resultatet likt de som drabbats av radiusfrakturer, men betydligt sämre resultat sågs hos patienter med frakturer som behandlats kirurgiskt jämfört med de som behandlats utan att ulna opererats. Då frakturerna delades upp efter röntgenologisk klassificering enligt AO/OTA 2018 tydliggjordes att tvärfrakturer hade ett betydligt bättre resultat då de behandlats utan operation av ulna och att dessa förmodligen inte skall opereras så länge som radius bidrar med stabilitet och riktning. De opererade patienterna hade oftare en felställd fraktur från början men det kunde inte bevisas att felställningen $\mathrm{i}$ sig gav det sämre resultatet.

Samma 97 frakturer i nedre delen av ulna klassificerades sedan i delarbete IV av tre oberoende observatörer enligt tre olika röntgenologiska klassifikationssystem; Biyani, AO/OTA 2007 och AO/OTA 2018. Klassifikationsprocessen upprepades efter minst 3 veckor. Tillförlitlighet och reproducerbarhet bestämdes för de respektive systemen. Tillförlitligheten var låg för AO/OTA 2007 och måttlig för Biyani och AO/OTA 2018. Reproducerbarheten var måttlig för alla tre systemen. Observatörerna ansåg att Biyani var det mest lättanvända systemet men att bildmaterialet ofta inte var tillräckligt för att kunna klassificera frakturerna korrekt och att en hel del frakturer inte passade in i de befintliga systemen. Slutsatsen var att en modifiering av Biyani samt bildmaterial som bättre kartlägger fraktursystemet till exempel genom en datortomografi, skulle kunna ge en mer exakt klassifikation med förbättrad tillförlitlighet och reproducerbarhet.

En förbättrad klassifikation av ulnafrakturer skulle kunna möjliggöra strukturerade utvärderingar av existerande och nya behandlingsmetoder samt utgöra basen vid utveckling av en behandlingsalgoritm för ulnafrakturer. Kirurgisk behandling är förmodligen det bästa för vissa frakturtyper, men för vilka kvarstår att utforska. 


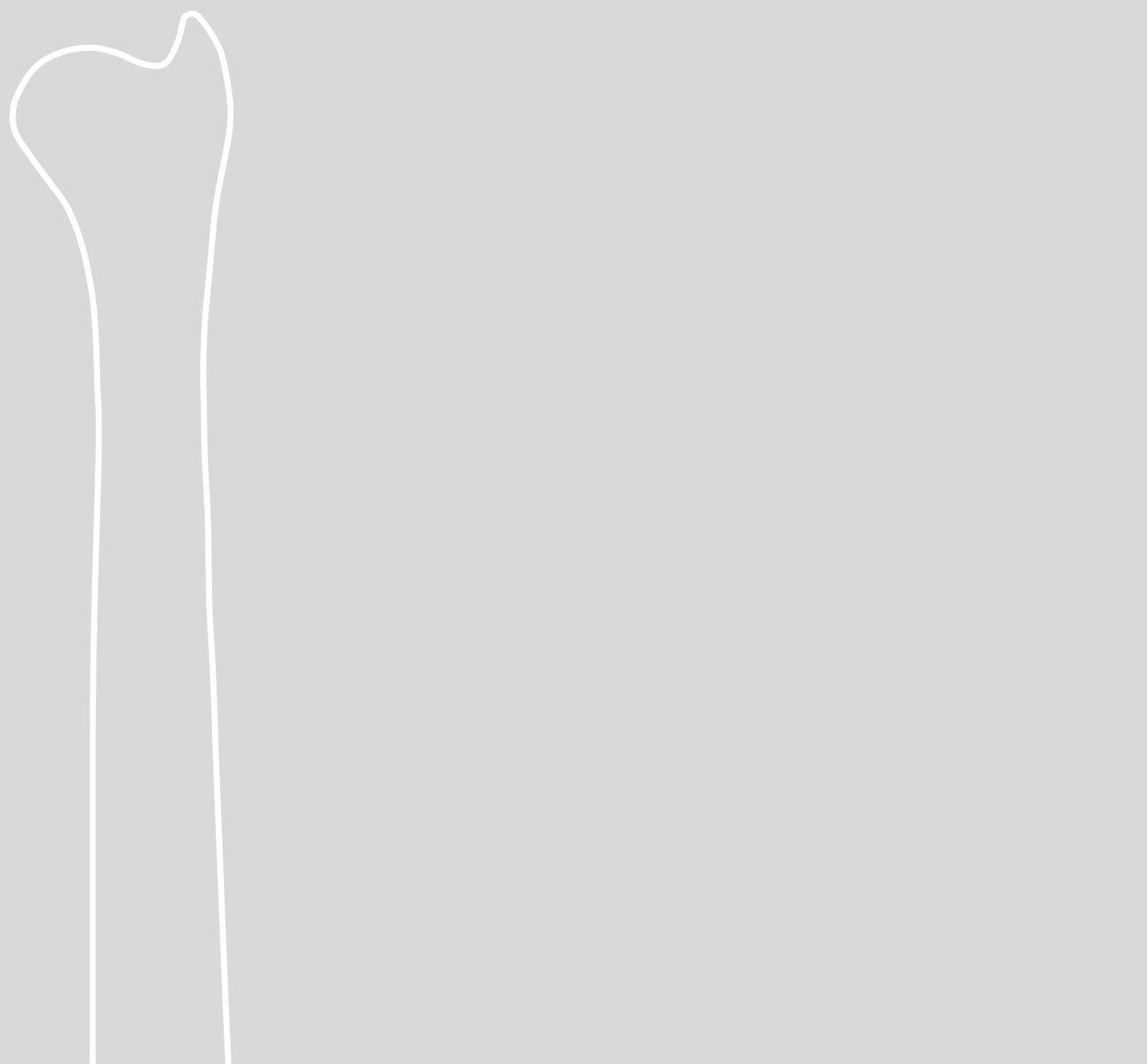




\section{List of papers}

20-Year outcome of TFCC repairs

Moloney M., Farnebo S., and Adolfsson L.

Journal of Plastic Surgery and Hand Surgery, 2018 Jun; 52(3): 193-197

II

Incidence of distal ulna fractures in a Swedish county: 74/100,000 personyears, most of them treated non-operatively

Moloney M., Farnebo S., and Adolfsson L.

Acta Orthopaedica, 2020 Feb; 91(1):104-108

III

Distal ulna fractures in adults - subcapitular, transverse fractures did not benefit from surgical treatment

Moloney M., Farnebo S., and Adolfsson L.

Manuscript. Under revision - Archives of Orthopaedics and Trauma

IV Poor reliability and reproducibility of three different radiological classification systems for distal ulna fractures Moloney M., Kåredal J., Persson T., Farnebo S., and Adolfsson L. Manuscript. Submitted. 


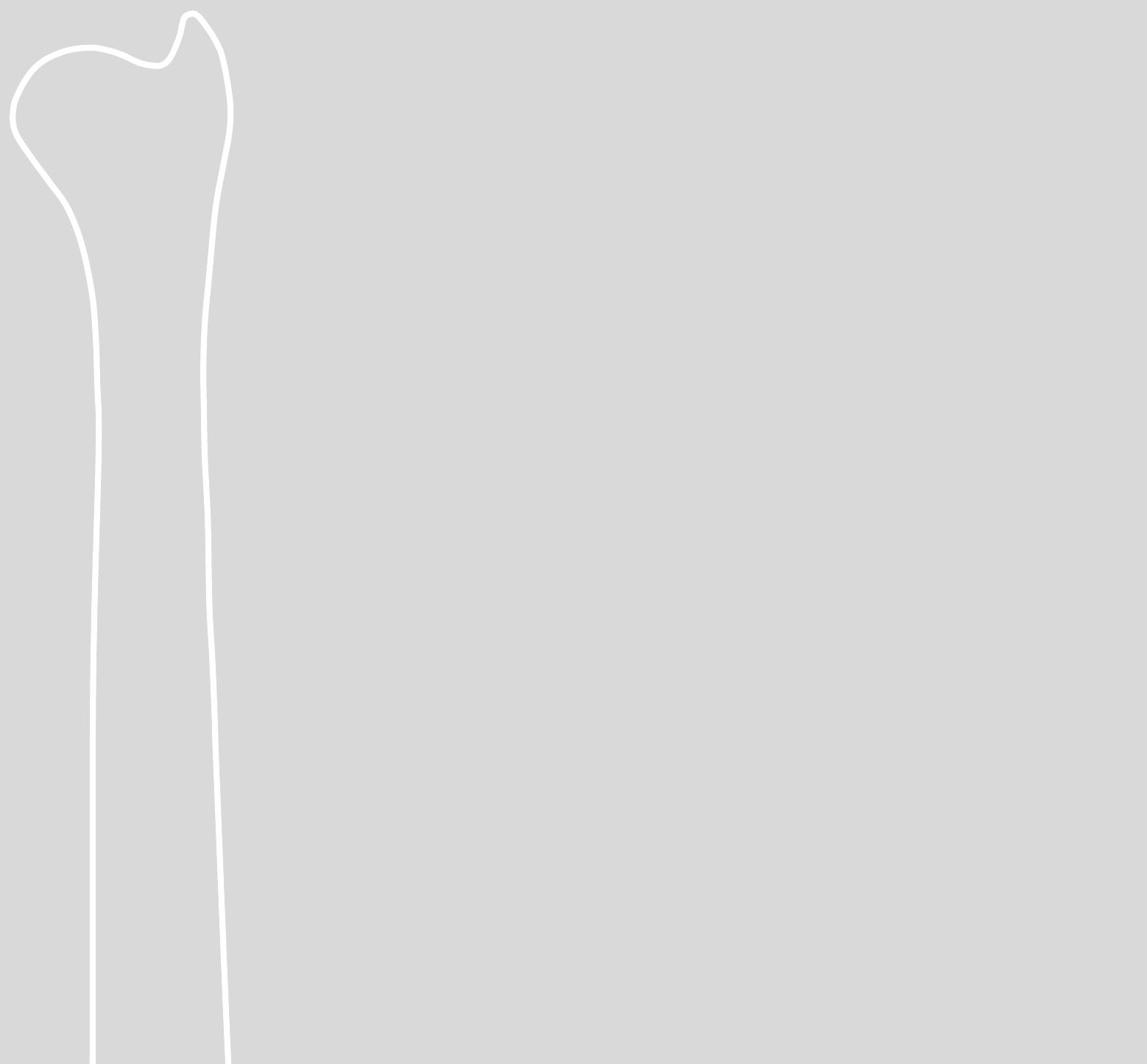




\section{Abbreviations}

AO Arbetsgemeinschaft für Osteosynthesefragen

CT Computed tomography

CBCT Cone beam computed tomography

DASH Disability of the Arm, Shoulder, and Hand

DISI Dorsal intercalated segment instability

DOB Distal oblique bundle

DRUJ Distal radio-ulnar joint

ECU Extensor carpi ulnaris

IOM Interosseous membrane

LT Luno-triquetral

MCID Minimum clinically important difference

MDC Minimum detectable change

MRA Magnetic resonance arthrography

MRI Magnetic resonance imaging

OA Osteoarthritis

OTA Orthopaedic Trauma Association

PREM Patient Reported Experience Measure

PROM Patient Reported Outcome Measure

PRWE Patient Related Wrist Evaluation

RUL Radio-ulnar ligament

SF-36 Short Form- 36

TFCC Triangular fibrocartilage complex

VISI Volar intercalated segment instability 


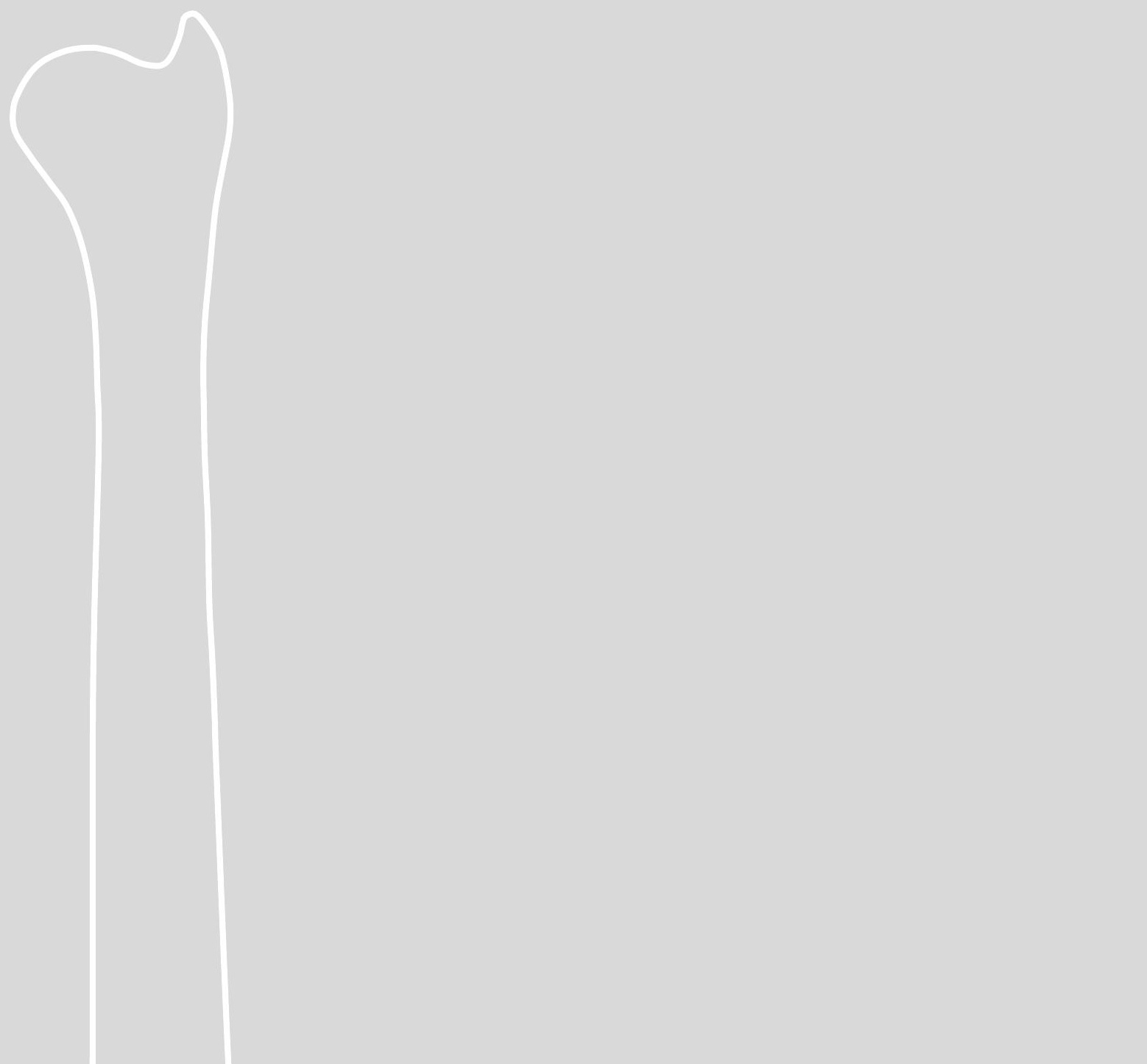




\section{Contents}

1 Introduction 19

2 Anatomy 21

3 Biomechanics 25

4 TFCC injuries 29

Diagnostics: Diagnostic imaging 31

Clinical examination 32

Arthroscopy 33

Treatment 34

5 Fractures of the distal forearm 37

Diagnostics 37

Radius 38

Ulna 39

6 Aims 45

7 Patients 47

8 Methods 49

Radiographs 49

PRWE 49

Fracture classification systems 51

Statistical tests 53

Data collection and assessments 53

9 Review of the papers and main results 57

10 Discussion 63

11 Conclusions 69

12 Future research 71

13 Acknowledgements 73

14 Reference 77

15 Papers 85 


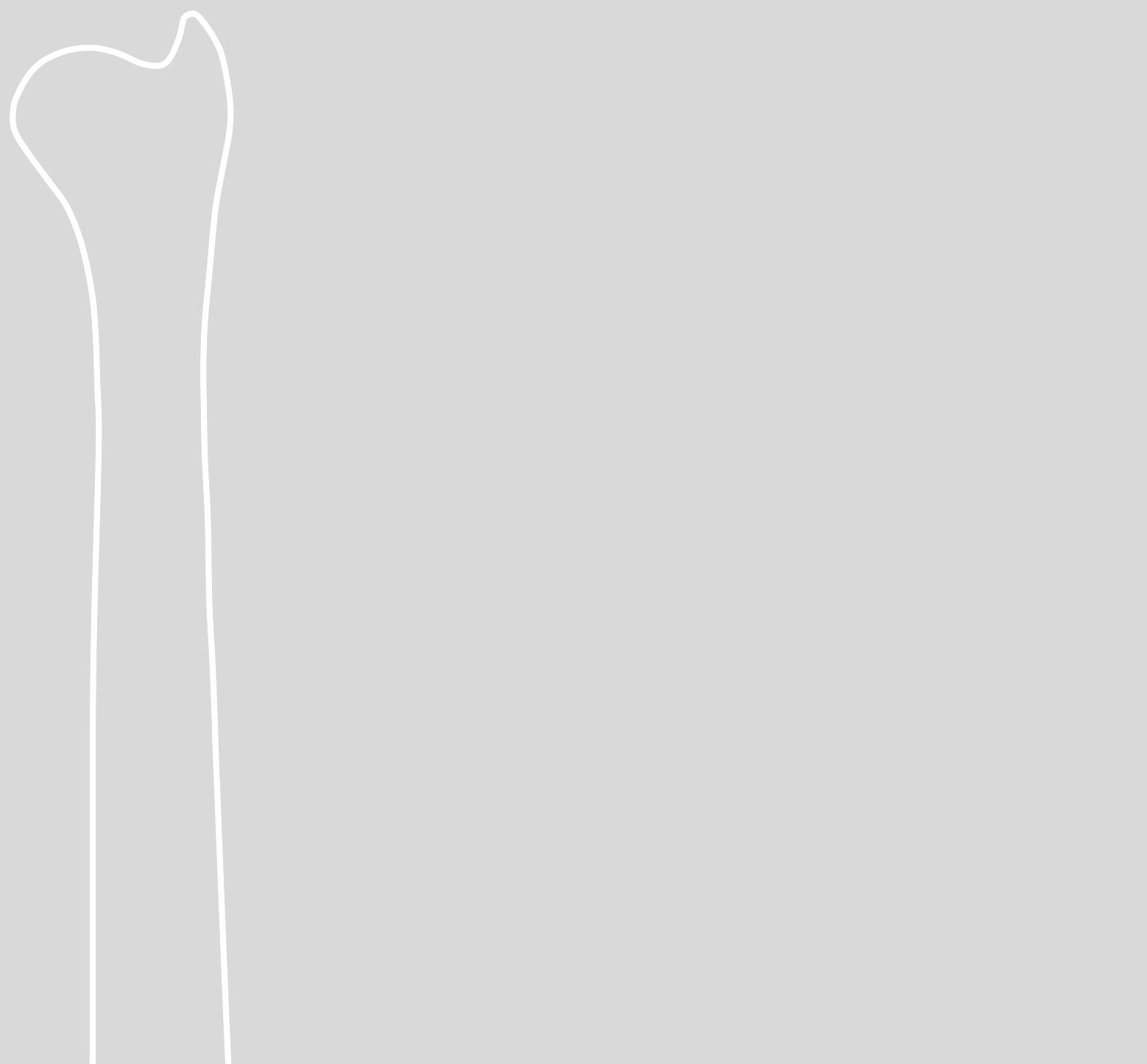




\section{Introduction}

A fall on an extended wrist is a common cause of injury seen in all emergency care units often resulting in fracture of the distal radius and more rarely fracture of the distal ulna and injury of the ligaments of the wrist. Fractures are usually easy to diagnose by radiographs. Ligament injuries, however, require a high level of suspicion and careful clinical examination by an experienced surgeon. Whereas there has been extensive research on distal radius fractures, much less is known about distal ulna fractures apart from the frequently occurring ulnar styloid fracture. Distal ulna fractures are uncommon and there is a lack of studies that examine how the patients perceive functional outcome and how these injuries should be treated.

Injuries to anatomic structures on the ulnar side of the wrist can result in persisting ulnar-sided wrist pain. This is sometimes described as the "black box" of the wrist, due to the many causes of wrist pain and the difficulty in treating them. For this reason, ulnar-sided wrist pain has also been likened to low back pain. Wrist pathology can be categorised as pain alone, pain with instability, or pain with arthritis. Pain alone may be caused by ligament injuries, capsular injury, or synovitis. Pain with instability may be the result of a tear/avulsion of ligaments such as the triangular fibrocartilage complex (TFCC), the extensor carpi ulnaris (ECU) subsheath, or luno-triquetral (LT) ligament. Pain with arthritis may be seen in ulnar impaction syndrome or arthritis in the distal radio-ulnar joint, often the result of previous fracture of the distal radius or ulna (Brogan, Berger et al. 2019). To diagnose the cause of ulnar-sided wrist pain, a careful history must be taken and the wrist examined thoroughly. Pain can be caused by injuries from acute trauma, chronic overuse, or chronic degenerative conditions (Sachar 2012).

Ulnar-sided wrist pain may cause frustration for the clinician since there are several possible causes and a risk for persisting pain despite treatment of the fracture or ligament injury. This thesis focuses on fractures of the distal ulna and the stabilizing structures attached in its fovea and styloid process i.e., the TFCC. The treatment of TFCC injuries has received much attention, but there is little information about long-term outcome and whether patients are satisfied. Regarding fractures of the distal forearm, much is known about distal radius fractures while ulna fractures have been somewhat overlooked. Not giving ulna the appropriate consideration when treating concomitant forearm fractures may result in a poorer outcome. We need to know more about how the ulna is usually fractured, functional results after treatment, and if radiographic classification can aid us in the treatment of these relatively uncommon fractures. 


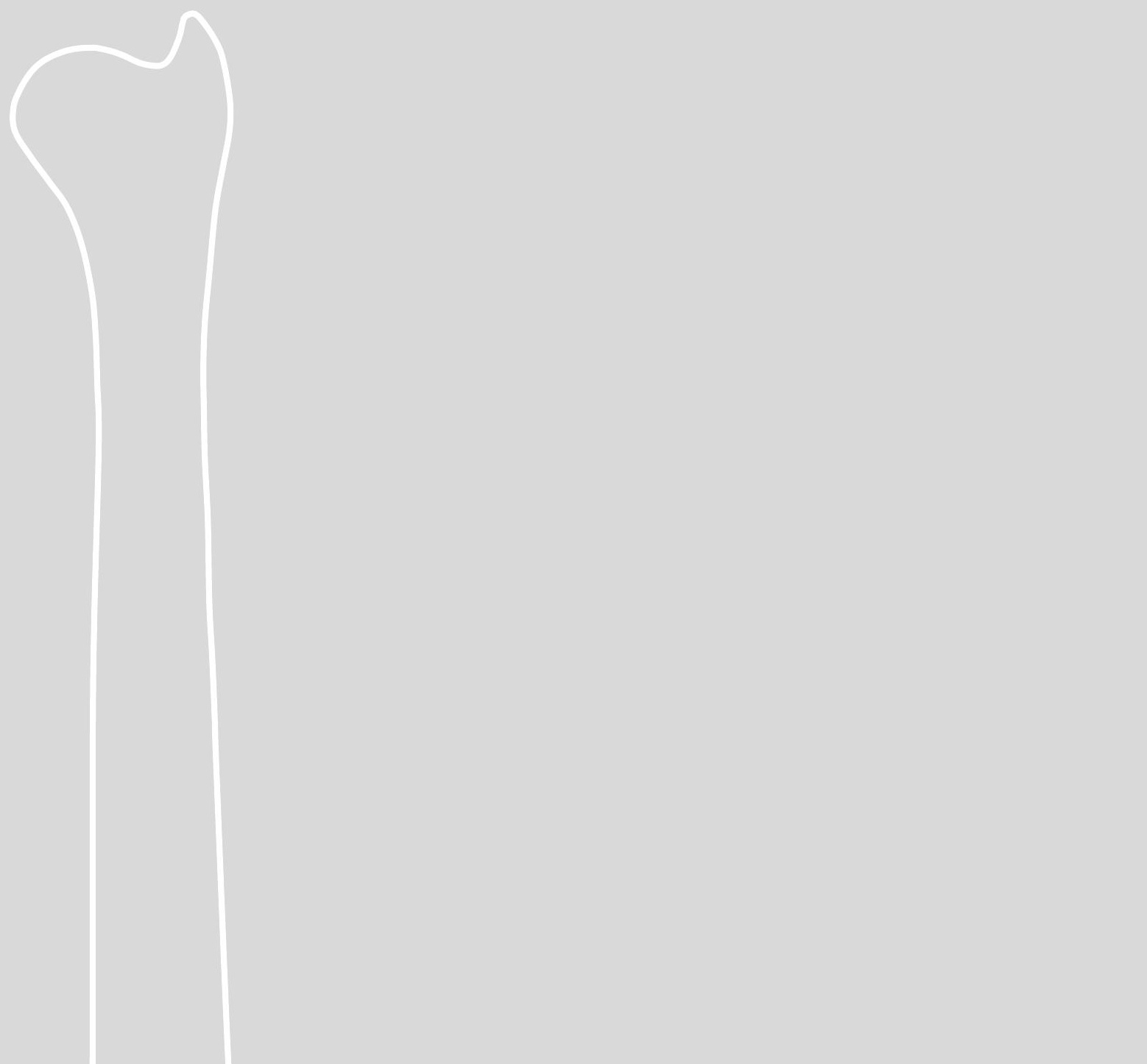




\section{Anatomy}

The wrist consists of the distal radius and ulna, eight carpal bones, and the bases of the five metacarpal bones. The carpal bones are further divided into a proximal and a distal row where the proximal row can be described as an intercalated segment since no tendons insert on these bones (Kijima and Viegas 2009). The proximal row consists of the scaphoid, lunate, triquetrum and pisiform, and the distal row of the trapezium, trapezoid, capitate, and hamate. There are important joints between the bones such as the distal radio-ulnar joint (DRUJ), the radio-carpal joint, the midcarpal joint, and the carpo-metacarpal joints.

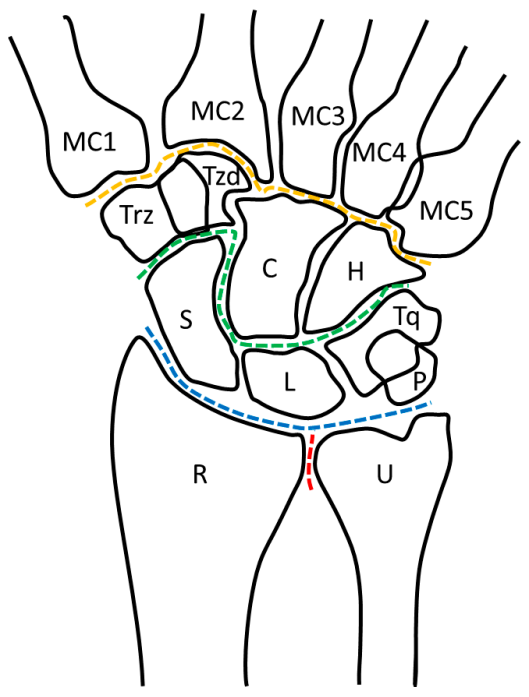

Figure 1. The anatomy of the wrist. $\mathrm{R}=$ Radius, $\mathrm{U}=\mathrm{U}$ Ina, $\mathrm{S}=\mathrm{Sc}$ Saphoid, $\mathrm{L}=\mathrm{Lunate}, \mathrm{Tq}=$ Triquetrum, $\mathrm{P}=$ Pisiform, Trz=Trapezium, Tzd=Trapezoid, C=Capitate, $\mathrm{H}=$ Hamate. DRUJ, radio-carpal joint, midcarpal joint, and carpo-metacarpal joints.

There are several carpal ligaments that guide and constrain the movements of the carpal bones relative to the metacarpals, the forearm bones, and adjacent carpal bones. These can be divided into extrinsic and intrinsic, based on their location (Taleisnik 1976). Extrinsic ligaments connect the forearm bones to the carpal bones whereas the intrinsic ligaments have both origin and insertion within the carpal bones. The extrinsic ligaments can be divided into dorsal ligaments, which are important secondary stabilisers of the scapho-lunate joint, and volar ligaments, that play a major role in stabilising the wrist. The strongest volar ligaments are the radio- 
scapho-capitate, the long radio-lunate, and the short radio-lunate. The most important intrinsic ligaments are considered by some to be the scapho-lunate and the lunotriquetral ligaments (Kijima and Viegas 2009).

The distal radio-ulnar joint is a complex articulation between the ulnar head and the sigmoid notch on the distal radius. There are two articular surfaces on the ulnar head; the seat, which articulates with the sigmoid notch, and the pole or dome which forms the surface under the fibrocartilage disc of the TFCC. Approximately $220^{\circ}$ of the ulnar head is covered by articular cartilage (Huang and Hanel 2012). The sigmoid notch is a shallow concave surface with a curvature radius twice as large as that of the ulnar head in the transverse plane. This leads to incongruity that allows both rotational and translational motion in two planes. The concavity of the notch can be categorised as flat face, ski slope, C type, or S type, where the flat face notch is the most common. The DRUJ can also show different configurations in the coronal plane. Tolat et al described these as type I parallel (55\%), type II oblique (33\%), and type III reverse oblique (12\%). In the coronal plane the articulation is congruent. In most notches there is also an extra-articular palmar osteo-cartilaginous lip that acts as a stable buttress preventing palmar dislocation of the ulna (Tolat, Stanley et al. 1996). The ulnar pole/dome can vary from being almost flat to more of a hemisphere. The distal ulna ends with the ulnar styloid that is the origin of the ulno-carpal ligaments and the superficial fibres of the radio-ulnar ligaments. At the base of the ulnar styloid is the fovea, a shallow richly vascularised concavity representing the centre of rotation for the DRUJ. The fovea is the primary attachment of the radio-ulnar and ulno-carpal ligaments. Dorsoradially to the styloid, the ECU tendon resides in its groove on the ulna (Huang and Hanel 2012). This groove and the overlying subsheath stabilises the ECU tendon as they form a fibro-osseous tunnel. The ECU subsheath attaches to the periosteum and extends to attach to the ulnar styloid and the dorsal radio-ulnar ligament (Omokawa, Gumpangseth et al. 2021). The length of the distal ulna relative to the radius is individual and is known as ulnar variance. An ulna longer than the radius is known as plus or positive variance and a shorter ulna as minus or negative variance (Nypaver and Bozentka 2021).

The radius and ulna are connected by the proximal annular ligament, the interosseous membrane (IOM), and distally the TFCC as well as the joint capsules. The TFCC consists of palmar and dorsal radio-ulnar ligaments (RUL), between these an articular disk, ulno-carpal ligaments, the ECU tendon subsheath, and the meniscus homologue. The TFCC receives its blood supply from the radio-carpal branches of the ulnar artery and the dorsal and palmar branches of the anterior interosseous artery. The central portion of the disc, however, is avascular. The ulnar nerve innervates the volar and ulnar portions and the posterior interosseous nerve the dorsal portion. The DRUJ and overlying skin is innervated by a transverse branch of the dorsal ulnar sensory nerve (Huang and Hanel 2012). The radio-ulnar ligaments extend from the sigmoid notch and divide into a deep (proximal) portion inserting in the fovea and a superficial (distal) portion inserting at the styloid base. The foveal insertion is the most important for DRUJ stability (Haugstvedt, Berger et al. 2006). The dorsal radio-ulnar ligaments insert at the dorsal rim of the sigmoid notch. The most superficial fibres contribute to 
the formation of the ECU tendon subsheath. The palmar radio-ulnar ligaments insert at the palmar rim of the sigmoid notch. The most superficial fibres of the palmar ligaments extend distally to form the ulno-lunate and ulno-triquetral ligaments (Berger 2001).

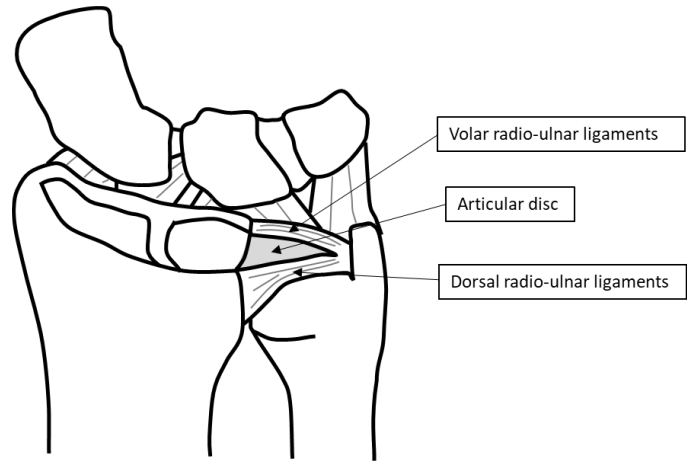

Figure 2. The TFCC

The morphology of the TFCC is associated with ulnar variance. In neutral variance, the TFCC is at a slight angle to a horizontal line from the sigmoid notch. In minus variance, the TFCC is more horizontal, shorter, and centrally thicker. In plus variance, the TFCC is thin, stretched distally, and arc shaped. Ulna plus variance may lead to ulno-carpal impaction with greater forces acting on the disc compartment of the joint, especially in rotation. The thin TFCC is also more vulnerable to these biomechanical forces (Vezeridis, Yoshioka et al. 2010). The radio-ulnar ligaments are the primary stabilisers of the DRUJ. Secondary stabilisers are the IOM, the ECU tendon, and pronator quadratus. The IOM provides longitudinal stability, DRUJ stability, and transfers load from the radius to the ulna. Especially the part of IOM named the distal oblique bundle (DOB), when present, is an important stabiliser of the DRUJ. DOB has been identified in 40-50 \% of forearms in cadaveric studies (Noda, Goto et al. 2009, Riggenbach, Conrad et al. 2013). The ECU tendon is a dynamic stabiliser by elevating the ulnar carpus while pressing the ulnar head in a volar direction during pronation. The pronator quadratus muscle contributes to DRUJ stability by bringing the distal ulna closer to the sigmoid notch during active pronation and passive supination (Huang and Hanel 2012). 


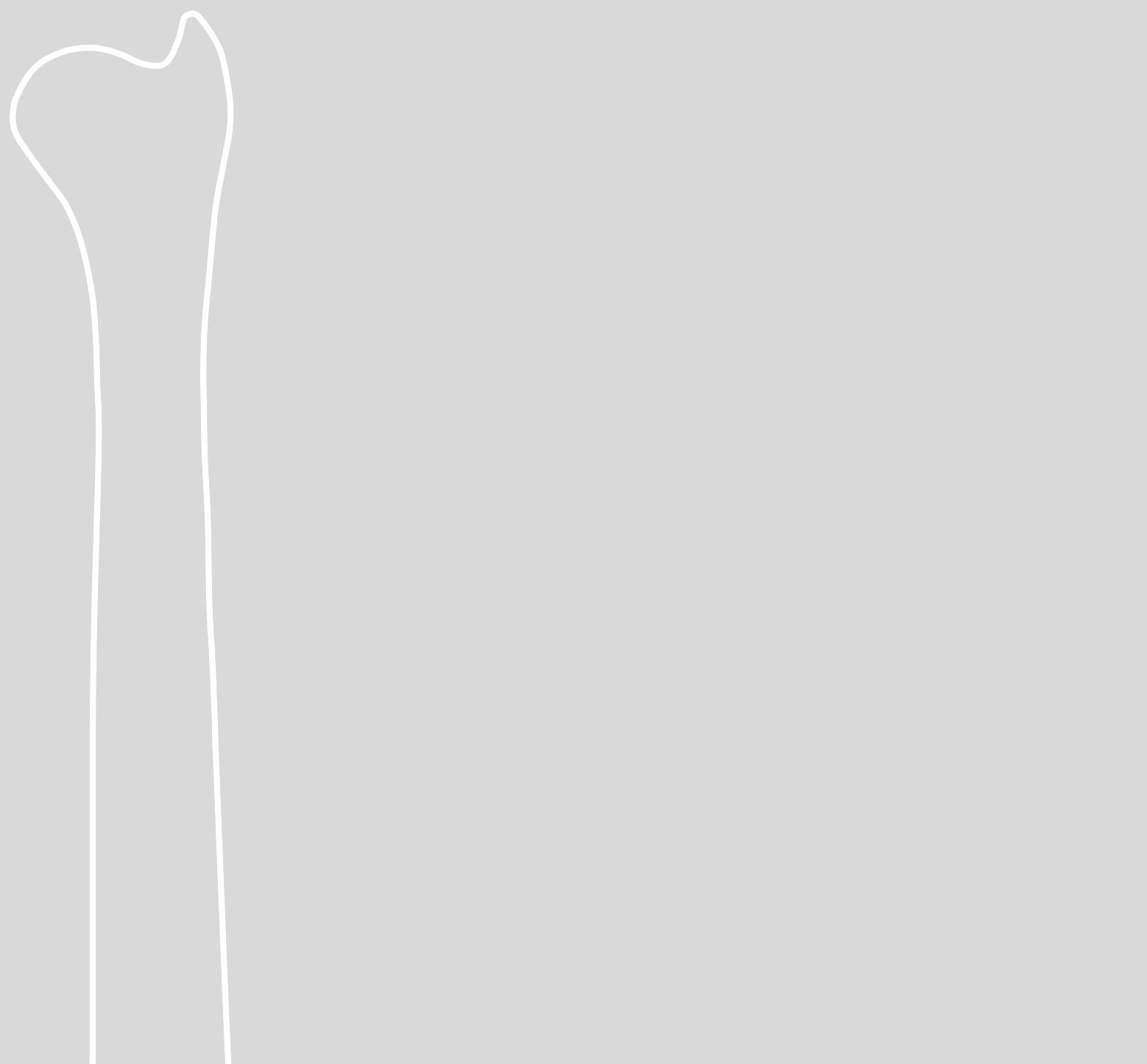




\section{Biomechanics}

In pronation and supination, the radio-carpal unit rotates around the fixed and stable ulna. Despite the ulna being the fixed bone, it is common in the literature to address translational movement to the ulna instead of the radius. For example in pronation the distal ulna translates dorsally and distally, whereas in supination the ulna translates volarly and proximally relative to the radius (Huang and Hanel 2012). In the neutral position, about $60 \%$ of the articular surfaces are in contact, compared to only about $10 \%$ in maximal pronation and supination, meaning 1-2 mm (Hagert and Hagert 2010). Most of the compressive forces on the wrist are transmitted through the radio-carpal joint in neutral ulnar variance, with only $18 \%$ through the ulno-carpal joint. The ulnocarpal load increases to $42 \%$ when there is a $2.5 \mathrm{~mm}$ ulnar positive variance (Huang and Hanel 2012).

Several biomechanical studies have been performed to evaluate the stabilising components of the DRUJ, with sometimes contradictory results. Af Ekenstam and Hagert found that the palmar RUL prevents dorsal dislocation of the ulnar head in full pronation, and in supination the dorsal RUL prevents palmar dislocation of the distal radius (af Ekenstam and Hagert 1985). Schuind et al, in contrast, showed the palmar RUL to be tense in supination and the dorsal RUL tense in pronation (Schuind, An et al. 1991). Kihara et al sectioned the IOM and found that the dorsal RUL was more important for stabilisation in pronation and the palmar RUL in supination (Kihara, Short et al. 1995). Hagert and Hagert showed that the radio-ulnar ligaments have a spiral configuration as they insert onto the ulnar head. This combined with centric and epicentric insertions of the deep and superficial portions of the radioulnar ligaments leads to continual shifts in tension of the various parts of the ligaments making DRUJ stability a constantly changing and dynamic process (Hagert and Hagert 2010).

The TFCC has been regarded the "hammock" of the ulnar carpus. Another way of looking at it is the "iceberg concept", which refers to the tip of the iceberg being the TFCC seen during radio-carpal arthroscopy. This part functions as a shock absorber and is much smaller than the "submerged" part. The "submerged" part can only be seen in DRUJ arthroscopy and represents the foveal insertion that stabilises DRUJ and the ulnar carpus. The larger size of this part corresponds to its greater functional importance (Atzei and Luchetti 2011).

When managing disorders of the DRUJ it's important to address all structures affecting biomechanics and stability. This has been structured into a treatment algorithm by Kakar et al, where the cause of joint dysfunction is divided into four pathologies, that all need to be addressed to improve outcome. The four pathologies are bony deformity (distal radius malunion and/or radioulnar length discrepancy), cartilage defect due to chronic dysfunction, TFCC injury and rupture or insufficiency of the ECU subsheath. Most DRUJ dysfunctions have more than one pathology that require specific treatment (Kakar and Garcia-Elias 2016). 


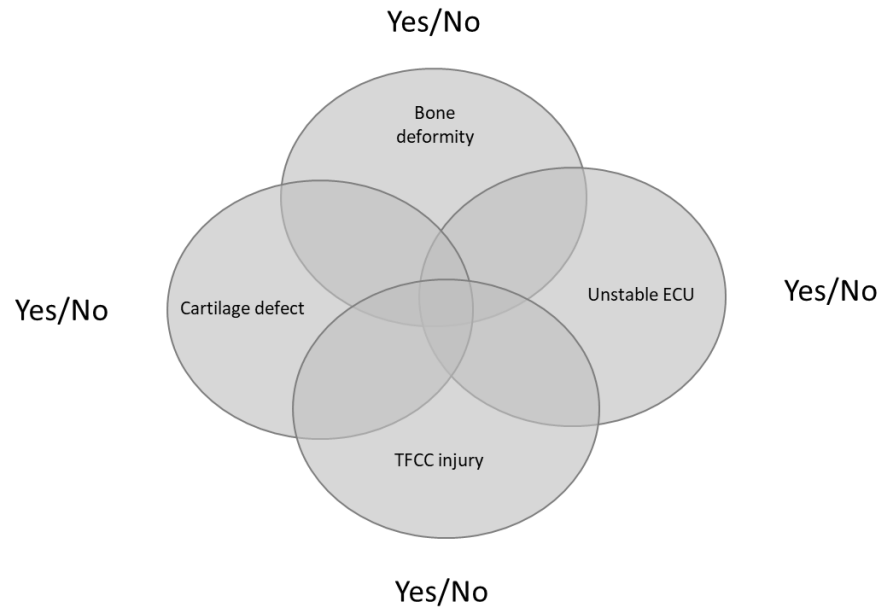

Figure 3. The Four-leaf clover algorithm, modified from Kakar S. and Garcia-Elias M. (Kakar and Garcia-Elias 2016) 


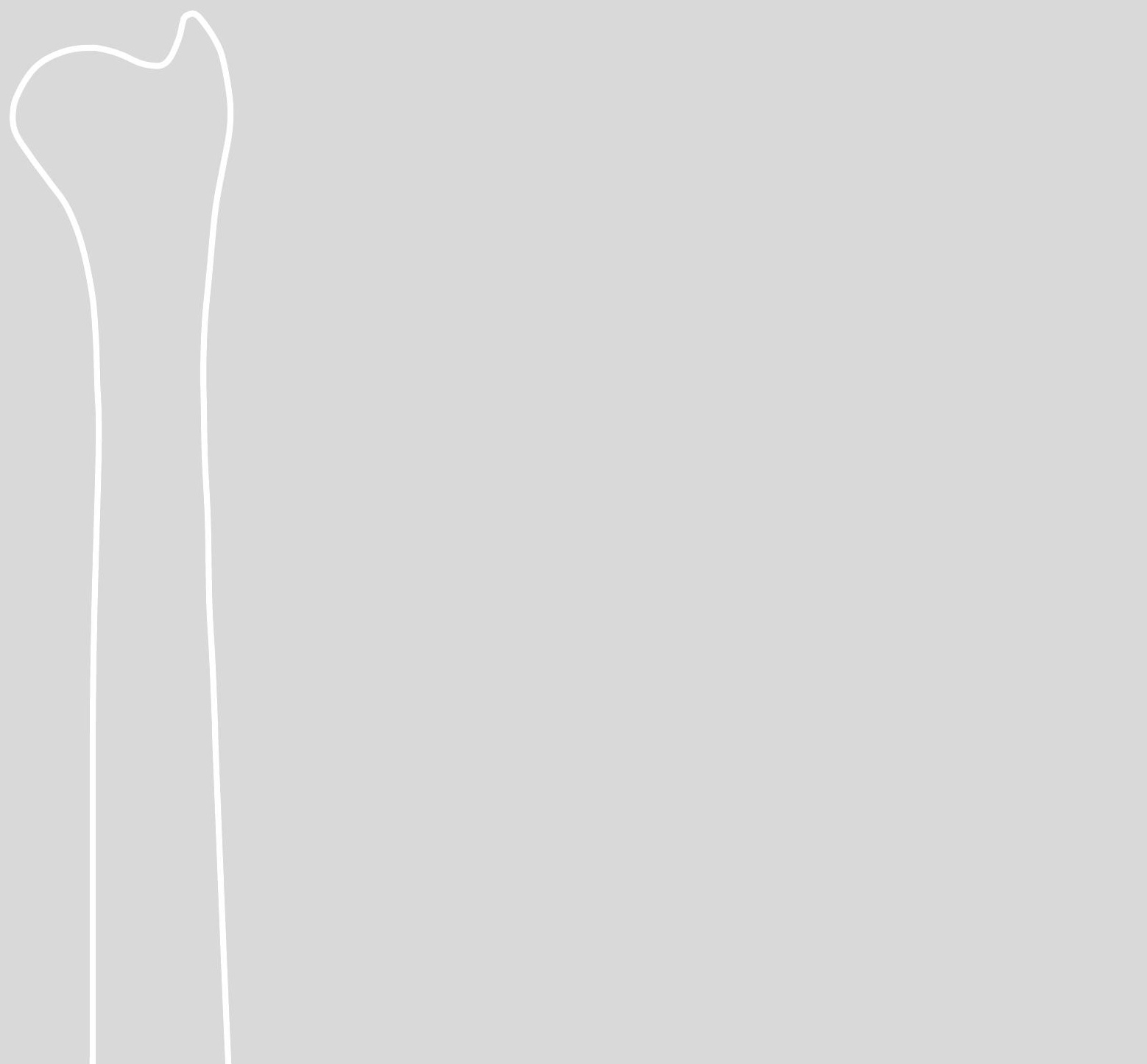




\section{TFCC injuries}

Injuries to the TFCC typically cause instability of the DRUJ and ulno-carpal joints and ulnar-sided wrist pain (Lindau, Adlercreutz et al. 2000). The pain is often increased during forced pronation and supination. While complete tears are strongly associated with instability of the DRUJ, partial tears can be seen in both stable and unstable DRUJ joints (Lindau, Adlercreutz et al. 2000).

Trauma that leads to tearing of the TFCC is often a fall on the outstretched hand producing an axial loading force or hyperpronation injury to the forearm. This is the same trauma that often results in a distal radius fracture. It is therefore not surprising that TFCC injuries are commonly associated with distal radius fractures and are seen in approximately 50-60\% (Ruch, Yang et al. 2003, Varitimidis, Basdekis et al. 2008). Tears of the TFCC have been suggested to start with an injury to the ECU subsheath progressing to tearing of the RUL from the base of the ulnar styloid on the palmar side, and finally spreading dorsally and radially (Scheer and Adolfsson 2012). If this is not addressed, it could have a negative impact on wrist function after otherwise successful fracture treatment, due to instability of the DRUJ and the ulno-carpal articulation. Already in 1814, Abraham Colles showed that instability of the DRUJ was associated with poor results after treatment of distal radius fractures. This has been confirmed in more recent studies where instability at clinical examination was associated with poor functional scores and high pain scores at follow-up (Lindau, Hagberg et al. 2000).

A TFCC injury diagnosed arthroscopically at the time of a distal radius fracture has not been shown to affect self-reported long-term results if left untreated. However, patients with a complete foveal TFCC tear will continue to have instability of the DRUJ, indicating that these injuries are unlikely to heal without treatment (Mrkonjic, Geijer et al. 2012). Since the central zone of the TFCC is avascular, tears located there have no chance of healing (Vezeridis, Yoshioka et al. 2010).

The most commonly used TFCC injury classifications are those of Palmer and Atzei. The Palmer classification divides TFCC lesions into traumatic (1) and degenerative (2). Traumatic injuries are further divided depending on the location of the tear, where class $1 \mathrm{~A}$ with central perforation or a tear of the disc is the most common traumatic type. Class $1 \mathrm{~B}$ signifies avulsion from the insertion point on the distal ulna. Tears of the distal insertion of the TFCC on the lunate are classed as 1C, while tears of the radial insertion on the sigmoid notch are classed as 1D. Class 2 tears are the result of a chronic load on the ulnar side of the wrist becoming progressively worse. Class 2A signifies wear of the TFCC without perforation, class 2B wear of the TFCC plus chondromalacia of the lunate and/or ulnar head, and $2 \mathrm{C}$ as $2 \mathrm{~B}$ plus perforation of the TFCC. Class 2D is as the others plus luno-triquetral ligament disruption. Finally, in class $2 \mathrm{E}$ there is degenerative arthritis of the ulno-carpal joint and occasionally DRUJ (Palmer 1989). Previous undiagnosed traumatic injury can also develop secondary degenerative changes making classification challenging (Adolfsson 1994). 


\begin{tabular}{ll} 
Class 1 & Traumatic injury \\
\hline 1A & Central slit \\
1B & Ulnar avulsion with/without distal ulnar fracture \\
1C & Distal avulsion (carpal attachment) \\
1D & Radial avulsion with/without sigmoid notch fracture \\
\hline Class 2 & Degenerative injury \\
\hline 2A & TFCC wear \\
2B & TFCC wear and lunate/ulnar chondromalacia \\
2C & TFCC perforation and lunate/ulnar chondromalacia \\
2D & TFCC perforation and lunate/ulnar chondromalacia \\
& and luno-triquetral ligament tear \\
2E & TFCC perforation and lunate/ulnar chondromalacia \\
& and luno-triquetral ligament tear and ulno-carpal OA \\
\hline
\end{tabular}

Table 1. Classification of TFCC injuries according to Palmer

In the Atzei classification, the Palmer $1 \mathrm{~B}$ tears are further divided into 5 classes. Class 0 - isolated ulnar styloid fracture without TFCC tear, meaning that DRUJ is stable. Class 1 - distal tear where DRUJ may be slightly lax, but where the ballottement test gives a hard end point, the trampoline test is positive, and the hook test is negative. Reduction in TFCC tension and consistency causes loss of the trampoline effect (positive trampoline test) (Hermansdorfer and Kleinman 1991). The hook test is performed by placing a probe under the peripheral edge of the TFCC and trying to displace it into the joint. If the deep fibres of the TFCC are intact this is not possible (Ruch, Yang et al. 2003). Class 2 - complete tear of both distal and proximal components of the TFCC. The DRUJ is lax with a soft ballottement test end point, and both hook and trampoline tests are positive. Class 3 - proximal TFCC tear with DRUJ laxity and a soft ballottement end point. The TFCC looks normal at radio-carpal arthroscopy but both trampoline and hook tests are positive. Class 4 - irreparable TFCC tear due to large defect or poor healing potential, and class 5 - DRUJ arthritis following a TFCC tear (Atzei and Luchetti 2011).

\begin{tabular}{llllll} 
Class & Description & Ballottement test & Trampoline test & Hook test & Appearance on RC arthroscopy \\
\hline 0 & Ulnar styloid fracture & Hard end point & Negative & Negative & Rupture \\
1 & Distal tear & Hard end point & Positive & Negative & Rupture \\
2 & Complete tear & Soft end point & Positive & Positive & Rupture \\
3 & Proximal tear & Soft end point & Positive & Positive & Intact \\
4 & Non-repairable tear & Soft end point & Positive & Positive & Rupture \\
5 & DRUJ OA & Soft end point & Variable & Variable & Variable \\
\hline
\end{tabular}

Table 2. Classification of TFCC injuries according to Atzei 


\section{Diagnostics}

\section{Diagnostic imaging}

Instability of the DRUJ does not relate to any changes on plain radiographs at the time of injury or 26 months later. Signs such as an avulsion fracture of the medial posterior portion of the distal radius or the base of the ulnar styloid raise suspicion, but radiographs may be completely normal despite a tear of the TFCC (Lindau, Hagberg et al. 2000). Other signs that give rise to suspicion include: widening of the DRUJ joint space, sagittal or ad latus dislocation of a distal radius fracture $>20^{\circ}$, and shortening of the radius $>5 \mathrm{~mm}$ (Spies, Langer et al. 2020). Radiographs can, however, identify chondromalacia of the lunate or ulnar head, degenerative changes of the DRUJ, dorsal intercalated segment instability (DISI), and volar flexed intercalated segment instability (VISI). The DRUJ can be further visualised by computed tomography (CT), where both wrists should be examined in the neutral position, pronation, and supination to identify subluxation or dislocation of the DRUJ, and sign of narrowed joint space as an indirect sign of osteoarthritis.

Magnetic resonance imaging (MRI) has a high sensitivity for soft tissue contrast and bone marrow changes. Because of the small size of the ligaments in the wrist, thin and contiguous slices are required and high signal-to-noise ratio images are essential. High magnetic field MRI (3.0 T) can achieve this. Combined with MRI arthrography (MRA), high sensitivity and specificity for TFCC injuries have been reported (Watanabe, Souza et al. 2010). Direct MR arthrography has a higher sensitivity in detecting central TFCC tears but a lower specificity and is furthermore an invasive technique. Conventional 1.5 T MRI has been reported to achieve just as good results with a sensitivity of $94.4 \%$ and specificity of $100 \%$ for detecting any type of TFCC tear (Cherian, Bhat et al. 2020). However, sensitivity and specificity are very userand equipment-dependent, and a meta-analysis from 2018 found the sensitivity and specificity for MRI to be 0.76 and 0.82 respectively, for MRA 0.78 and 0.85 , and for CT arthrography 0.89 and 0.89 . The diagnostic accuracy was higher for central TFCC injuries than for foveal tears (Treiser, Crawford et al. 2018).

The fundamental problem with diagnostic imaging of wrist instability is that static images produced in even the most sophisticated CT or MRI machines only allow indirect assessment of the dynamic problem. As described previously, different parts of the TFCC are tense in different pronation/supination positions, and changes with motion cannot be detected in pictures taken while the wrist is still and relaxed. In recent years, dynamic CT (4D-CT) illustrating carpal kinematics has been developed, and might help to identify dynamic carpal instability in the future (Pallaver and Honigmann 2019). 


\section{Clinical examination}

Instability of the DRUJ is subjective while clinical examination detects laxity. By definition, increased laxity does not imply symptoms of instability (Scheer and Adolfsson 2011). When assessing joint laxity, it is important to compare with the contralateral, hopefully uninjured, side. On examination, there may be ulnar swelling, the caput ulnae is often prominent, pronation and supination may provoke pain, and clicking or snapping of the ECU tendon might be felt during forearm rotation (Spies, Langer et al. 2020). The ulnar fovea sign is positive if there is tenderness when palpating the "soft spot" between the ulnar styloid, pisiform, and flexor carpi ulnaris tendon. This tenderness should liken their existing pain, and be absent in the other wrist. The ulnar fovea sign is reported to have a high sensitivity and specificity for disruption of the foveal insertion of the TFCC and/or ulno-triquetral ligament injury (Tay, Tomita et al. 2007). The dorsopalmar stress test is performed by holding the distal radius firmly while trying to translate the distal ulna dorsally and volarly. The extent of translation is then graded depending on the amount of laxity. The press test is performed by the patient pushing on his/her hands to stand up from an armchair. If this provokes ulno-carpal pain, the test is considered positive (Spies, Langer et al. 2020). Stability of the DRUJ can also be assessed with the piano key test in which force is applied to the ulnar head while the wrist is stabilised in pronation. This test is positive if the ulnar head returns to its normal position when the force is removed (Vezeridis, Yoshioka et al. 2010).

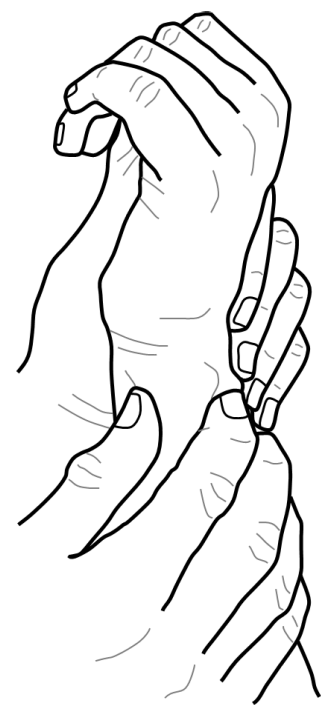

Figure 4. Dorsopalmar stress test 


\section{Arthroscopy}

Wrist arthroscopy was first performed in humans in the early 1970s (Watanabe 1972). Equipment has improved over time making it possible to both diagnose and treat a variety of conditions. Arthroscopy is performed with axial traction to create space for the scope and instruments. The arm is fixed to the table with the elbow flexed $90^{\circ}$ and the hand attached to a traction tower. It can be performed with or without irrigation (dry arthroscopy). The radio-carpal portals are named after their relation to the extensor compartments. The 3-4 portal is the key to wrist exploration. Other radiocarpal portals are 6R (radial to the ECU tendon), 4-5 and 6U (ulnar to the ECU tendon), and 1-2. The midcarpal portals are MCU (ulnar), MCR (radial,) and STT (scaphotrapezio-trapezoid). The distal radio-ulnar portals are the DRUJ portal, the direct foveal portal and the proximal DRUJ portal. There are also palmar portals that are not frequently used (Whipple, Marotta et al. 1986).

Wrist arthroscopy is the gold standard for diagnosing and classifying TFCC lesions. The TFCC can be visualized via the 3-4 portal, and with a hook via the $6 \mathrm{R}$ portal the tension and integrity of the TFCC can be assessed. The trampoline effect should be tested with the hook, showing tension and elasticity of the TFCC (Hermansdorfer and Kleinman 1991). Loss of trampoline effect is seen in complete tears. The hook test is performed by trying to pull the foveal insertion towards radius using the hook. When a ripple effect on the TFCC is seen, the test is positive. A third test is the ghost sign, where the hook is inserted into the DRUJ and a "ghost" effect is seen on the radiocarpal aspect of the TFCC (Mathoulin 2015). The hook test is the most accurate in evaluating all forms of tear, in particular when detecting proximal and complete tears where the foveal insertion is disrupted. The trampoline test is the most sensitive for detecting distal tears (Atzei, Luchetti et al. 2021).

Dry arthroscopy was developed by del Piñal and colleagues and is especially suitable in the diagnosis and treatment of ulnar-sided wrist disorders (del Pinal, Garcia-Bernal et al. 2007). The advantage of dry arthroscopy is that floating synovial villi obscuring the view are avoided, sequential open procedures are easier because tissues are not distended by saline, and it is possible to use larger instruments since larger portals can be made when loss of distension is not an issue. In procedures requiring a thermal probe or debridement of a joint, dry arthroscopy can be combined with temporary washouts and repeated saline injections (Burnier, Herzberg et al. 2021). 

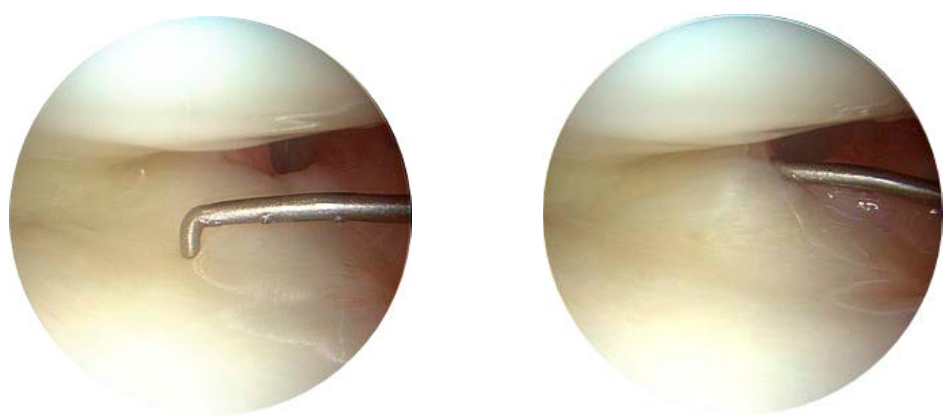

Figure 5. Dry arthroscopy showing an intact TFCC. The trampoline test on the left side and the hook test on the right side.

\section{Treatment}

Treatment of traumatic TFCC injuries can be performed in the acute phase if the injury is diagnosed early. However, detection of these injuries is often delayed, in which case repair at a later stage comes into question. If much time has passed since injury, it might not be possible to use the remnants of the TFCC for repair and reconstruction may then be the only possibility. In the 90s, Mikic et al suggested that acute TFCC injuries could be treated by closed reduction of the DRUJ and percutaneous radio-ulnar transfixation with Kirschner wires with the forearm in neutral rotation. In cases with displaced fracture of the base of the ulnar styloid, this was reduced and fixed with an encircling or intraosseous suture. This method of treatment was shown to achieve good results in isolated TFCC tears but in cases with associated forearm fracture the outcome could be worse (Mikic 1995). Many changes have occurred since then, both treatment strategies and postoperative rehabilitation. Transfixation is no longer performed and immobilisation time has become successively shorter with more active rehabilitation.

Watanabe et al suggested using the Palmer classification for determining treatment as follows: type $1 \mathrm{~A}$ tears of the avascular disc can be treated by arthroscopic debridement; type $1 \mathrm{~B}$ and $1 \mathrm{C}$ tears that are in the peripheral vascular zone can be treated with open or arthroscopic repair; type 2 degenerative tears, often secondary to ulnar impaction syndrome or repetitive loading, usually originate in the central avascular zone and may also be treated by arthroscopic debridement if surgical treatment is indicated. If there is ulnar impaction this must also be addressed, either by extra-articular ulnar osteotomy or arthroscopic intra-articular wafer resection (Watanabe, Souza et al. 2010). Corrective osteotomy of the radius is an alternative.

Although there is a paucity of well performed prospective randomised trials, more and more results point towards the use of similar treatment algorithms. Spies et al suggested in a recent review the following treatment algorithm: In osseous avulsion of the TFCC where intraoperative Ballottement test shows increased laxity of the DRUJ, the ulnar styloid is fixed. In tears of superficial fibres (Atzei 1), arthroscopic fixation of the superficial fibres to the capsule is recommended while tears of the deep 
fibres are reinserted arthroscopically or conventionally through two parallel drilled tunnels from the fovea or with suture anchors. They also recommend that complete tears of both superficial and deep fibres (Atzei 2) should be repaired in a similar fashion, dealing with the deep fibres as described above and the superficial fibres reinserted at the base of the styloid through a third bone tunnel distal to the first two. If the TFCC is irreparable (Atzei 4), the Adam's procedure is an alternative (Spies, Langer et al. 2020). The Adam's procedure was developed by Brian D. Adams to reconstruct the palmar and dorsal radio-ulnar ligaments to restore DRUJ stability. A tendon graft, for example the palmaris longus, is used to stabilise DRUJ by being secured in a dorsopalmar bone tunnel at the distal ulnar corner of the radius and then led through a second bone tunnel through the ulnar fovea to the ulnar neck where the limbs of the graft are wrapped around the ulna, tied together and secured with sutures (Lawler and Adams 2007). The recommendations by Spies et al are similar to those suggested by Atzei et al who also recommended that class 3 tears be treated by foveal reinsertion using transosseous sutures or suture anchors, and class 5 tears by resection arthroplasty or prosthetic replacement (Atzei and Luchetti 2011). Anderson et al compared open versus arthroscopic repair of TFCC tears and showed no statistical difference between methods regarding pain, DASH, grip strength, or range of motion after 43 months (Anderson, Larson et al. 2008). Luchetti et al made a similar comparison and found better postoperative wrist pain scores, Mayo wrist score, DASH, and PRWE in both groups. The DASH scores were significantly better in the arthroscopic repair group, but no differences between groups were seen in the other parameters (Luchetti, Atzei et al. 2014). Ruch et al evaluated acute repair of complete peripheral TFCC-tears at the time of a distal radius fracture. They included 13 patients and obtained excellent or good result in $92 \%$ with less pain and greater stability of the DRUJ (Ruch, Yang et al. 2003).

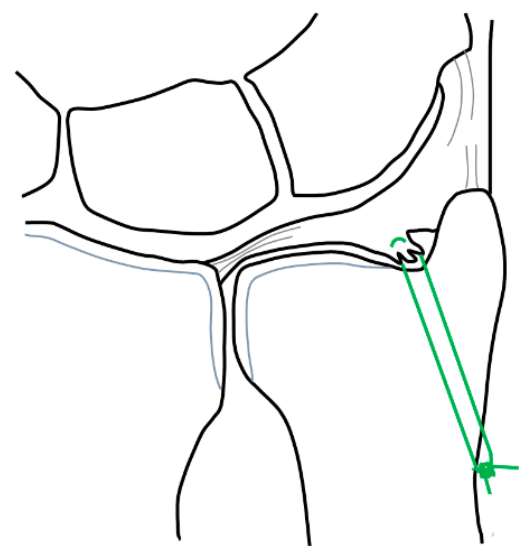

Figure 6. A foveal TFCC repair

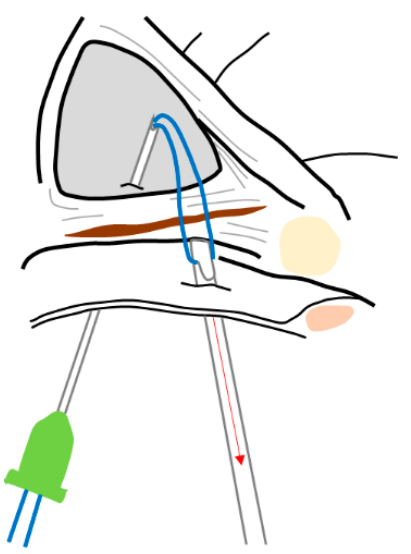

Figure 7. A peripheral TFCC repair 


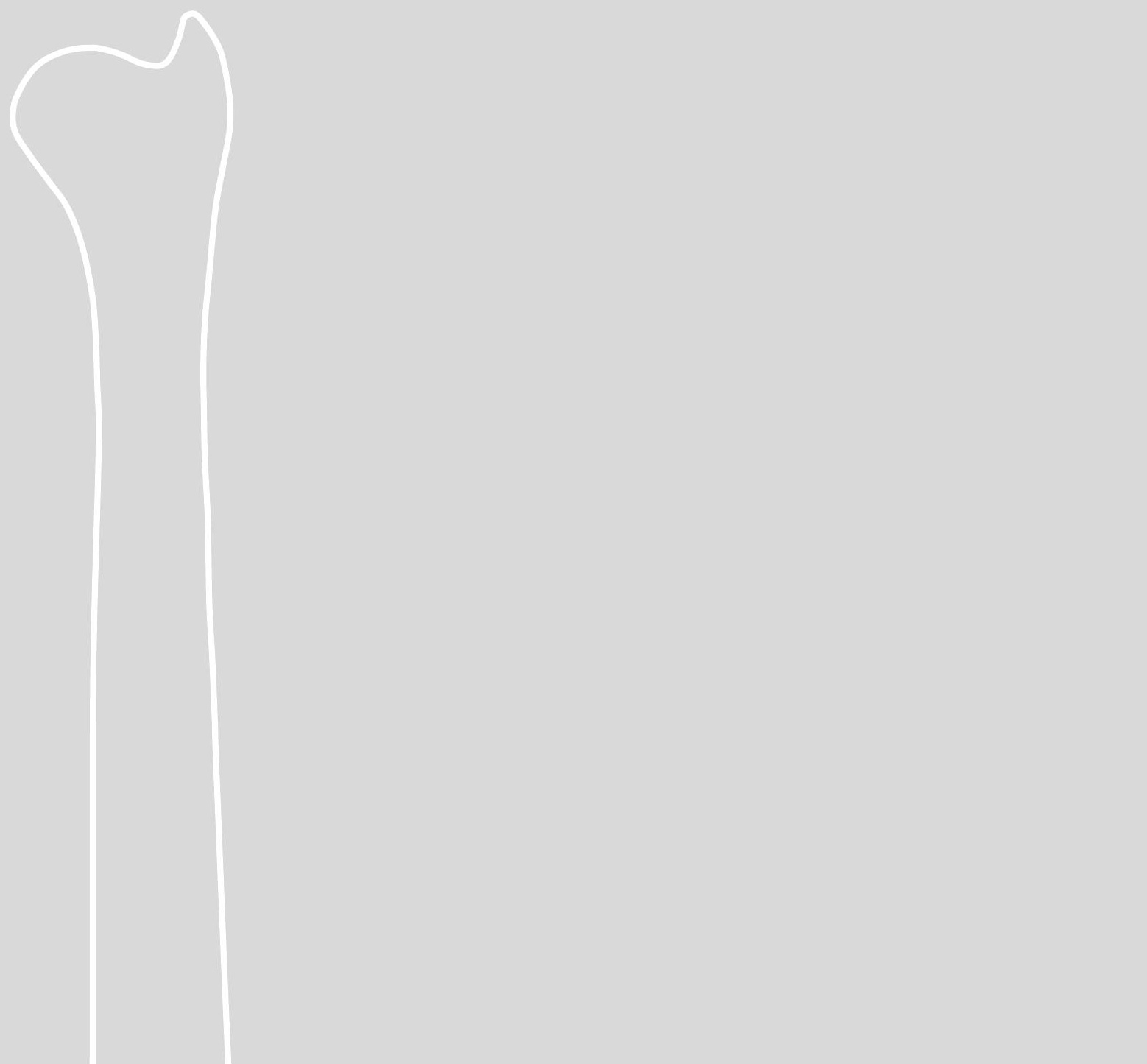




\section{Fractures of the distal forearm}

\section{Diagnostics}

Conventional radiography can usually identify a fracture of the distal forearm. The projections of the wrist are routinely taken with a posteroanterior and a lateral view. With comminuted or intra-articular fractures, standard radiographs might not be enough to determine the fracture pattern. In these cases, computed tomography (CT) might be helpful (Richards and Deal 2014). Standard radiography has been reported to be false-negative in up to $40 \%$ of cases. Fractures not visible on plain radiographs, sometimes called "occult", can usually be detected by CT or MRI. CT has high resolution and provides multiplanar and 3D reconstructions. MRI can also identify a bone contusion because of subcortical trabecular microfractures (Bruno, Arrigoni et al. 2019). If plain radiographs do not show a fracture but clinical suspicion is high, MRI can detect a bone contusion/bruising of the bone in as many as $50 \%$. A fracture line may also be found but this is less common (Sadineni, Pasumarthy et al. 2015). Fractures are identified as a low-signal linear lesion on T1-weighted images, surrounded by a large area of bone marrow oedema. Bone contusions include bleeding, infraction and oedema caused by microscopic compression fractures of the cancellous bone. Occult bone injuries are a heterogeneous group lying between these two extremes. The bone oedema pattern is like a footprint left behind at injury and can give insight into the mechanism of the injury (Sadineni, Pasumarthy et al. 2015).
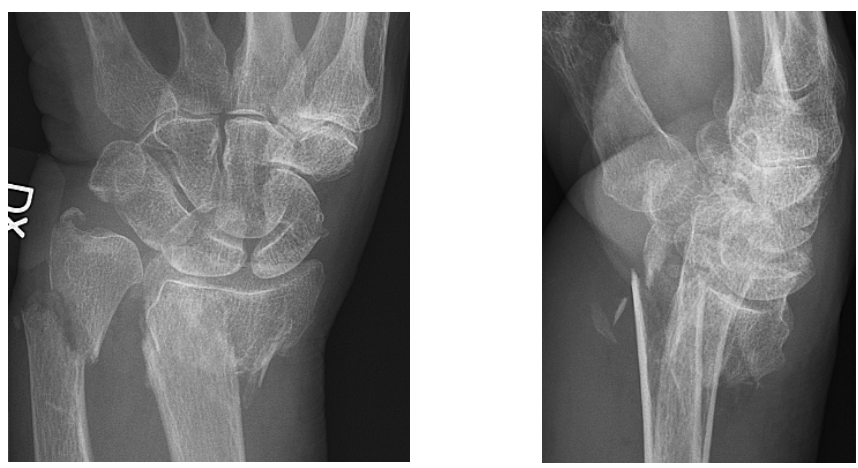

Figure 8. Posteroanterior and lateral projection of distal forearm fractures 


\section{Radius}

Fracture of the distal radius is the most common fracture in adults with an incidence of 258/ 100,000 person-years and is usually caused by a fall from standing height. The incidence has been shown to increase with slippery weather in countries with icy winters (Flinkkila, Sirnio et al. 2011). Distal radius fracture is more common in women, where the incidence increases after menopause because of demineralization of the skeleton due to low oestrogen levels. Distribution is bimodal with younger males and older females. High-energy trauma and intra-articular fractures are more frequent in non-osteoporotic patients (Court-Brown and Caesar 2006). In older persons, decreased neuromuscular control increases the risk for falling (Wilcke, Hammarberg et al. 2013). Between the 1950s and 1980s the incidence almost doubled in Sweden, but has since remained stable or has even decreased, possibly due to osteoporosis prevention programs (Brogren, Petranek et al. 2007). Almost $50 \%$ of patients who visit the emergency department because of trauma to the wrist are found to have a fracture of the distal radius, ulna or carpal bones, mostly the distal radius (Mulders, Bentohami et al. 2019).

Distal radius fractures are often associated with ligament injuries. A prospective study showed that patients with an increase in ulnar variance $>2 \mathrm{~mm}$ at the time of injury had four times greater risk for a Geissler III scapho-lunate ligament injury, and intra-articular fractures were associated with a two-fold increase in scapholunate dissociation seen in radiographs after 1 year (Forward, Lindau et al. 2007). Chondral lesions are also commonly associated with displaced distal radius fractures and can be diagnosed by arthroscopy in $32 \%$ (Lindau, Arner et al. 1997).

\section{Treatment}

Distal radius fractures are usually treated by closed reduction and a cast, but they may require external fixation, percutaneous pinning, or internal fixation with volar plates. Displaced fractures that heal with malunion are associated with greater arm-related disability one year after the injury (Brogren, Hofer et al. 2011). Malunion, defined as bone healing in a position that markedly deviates from the normal, is the most common complication after distal radius fracture, and more often occur after nonsurgical treatment. The displacement is often dorsal angulation (volar is not as common), loss of radial inclination, and/or height and rotational deformities. There may also be intra-articular displacement with step-off or a gap. Malunion leads to altered biodynamics that, if untreated, can lead to osteoarthritis, pain, limited mobility, or dysfunction. A decrease in radial inclination can change the direction of the flexor tendons resulting in weakness of grip. Dorsal angulation can result in incongruity of the DRUJ and tightening of the IOM limiting forearm rotation. This type of malunion can cause carpal instability, where there is either dorsal radial subluxation of the wrist with maintained midcarpal alignment or an adaptive midcarpal DISI (Katt, Seigerman et al. 2020). Dorsal angulation shifts the axial load dorsally and ulnarly and decreases the joint contact area. This means that the pressure distribution on the radial articular surfaces become more concentrated which in turn can lead to osteoarthritis 
(Prommersberger, Pillukat et al. 2012). Dorsal angulation can limit flexion and supination, whereas volar angulation can limit extension and pronation. Radial shortening can shift the load from the radio-carpal to the ulno-carpal joint and also cause the soft tissue stabilisers of the DRUJ to become tighter, leading to reduced pronation/supination and wrist pain (Katt, Seigerman et al. 2020). Angular and shortening deformity can affect the DRUJ through an altered axis of rotation, reduced congruity, reduction of the radio-ulnar contact area, and limited pronation/supination. Radial shortening can increase strain on the TFCC which in turn can lead to disruption of the deep portion of the dorsal radio-ulnar ligament (Prommersberger, Pillukat et al. 2012). Healing with dorsal angulation and translation results in a progressive increase in force and torque at the distal ulna. This in turn may cause residual ulnar-sided wrist pain and dysfunction (Ferreira, Greeley et al. 2015).

The problem with distal radius fractures is that there is still no gold standard when it comes to treatment. No surgical method has been proven to generate superior result and no single factor is proven associated with outcome (Hove LM 2014).

\section{Ulna}

Distal ulna fractures are much less common than distal radius fractures, and a metaphyseal ulna fracture is seen in $5.6 \%$ of patients with a distal radius fracture (Biyani, Simison et al. 1995). They are often caused by a fall on an outstretched arm with the wrist extended and there is often a concomitant fracture of the distal radius. Isolated distal ulna fractures are even rarer and usually caused by a focal blow to the ulnar border of the forearm, a so-called night stick fracture. The distal fragment including the metaphysis is often small, but has a relatively large articular surface, making internal fixation difficult (Ring, McCarty et al. 2004). Fractures of the distal ulna may result in incongruence and instability of the DRUJ, and potentially lead to chronic pain and limited forearm rotation (Kvernmo 2014). They can also lead to bridging callus between the radius and ulna, an altered DRUJ relationship, and non-union. In concomitant fractures (styloid fractures excluded) the distal ulna fracture is usually a simple extra-articular fracture. Such fractures may leave the DRUJ intact, but followup has shown ulnar plus variance, separation of the DRUJ, and bridging callus (Biyani, Simison et al. 1995).Combined distal radius and ulna fractures are usually seen in older patients with osteoporosis (Kim, Kim et al. 2016). 

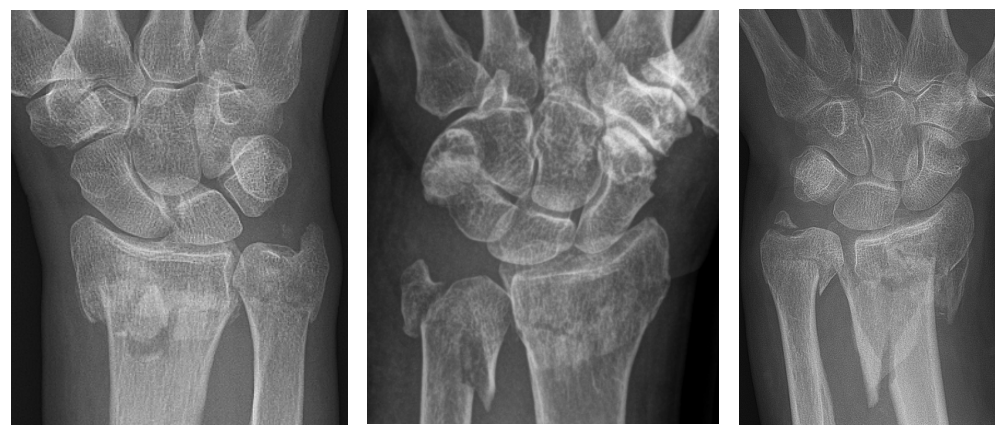

Figure 9. Examples of distal ulna fractures

The ulnar styloid is commonly fractured at the same time as the distal radius. More than $40 \%$ of distal radius fractures have an associated ulnar styloid fracture (Logan and Lindau 2008), and 55-70 \% of these will go on to non-union. A styloid fracture appears not to have a negative impact on functional outcome and is therefore left untreated unless it involves a part of the metaphysis or in the setting of DRUJ instability (Richards and Deal 2014). A styloid non-union can cause ulnar styloid triquetral impaction. The patient often complains of ulnar sided wrist pain when placing the hand on the hip or in the back pocket. It is important to relate radiographic findings of non-union with the patient's symptoms and clinical examination. The ulnar styloid non-union can cause agonising pain as a foreign body in the ulnar carpus, be associated with instability of the DRUJ, or have no clinical relevance (del Pinal 2010).

\section{Treatment}

Whereas much research has been carried out on the treatment of distal radius fractures, much less is known about treatment of fractures of the distal ulna. It remains unclear when a distal ulna fracture should be internally fixed or when conservative treatment with or without immobilization is adequate. Conservative treatment with immobilisation can be achieved by a cast below or extending above the elbow. The purpose of a short cast is to prevent angulation and misalignment of the reduced fracture while a cast above the elbow also prevents pronation and supination and hence rotation of the fragments. If no immobilisation is chosen the fracture should be considered stable and soft tissue stabilisers like the IOM keep the fracture in place. The choice of treatment is influenced by the mechanism of injury, fracture pattern, displacement, and associated injuries. A Cochrane review concerning treatment of isolated diaphyseal ulna fractures found no randomised controlled trial comparing surgical versus conservative treatment. They concluded that there was no evidence that a cast above the elbow has any advantage when it comes to healing rate or pain relief compared to a below elbow cast or brace (Handoll and Pearce 2012). A comparison of above or below elbow casts in distal forearm fractures in children came to the same conclusion, and also that a significantly greater proportion of patients with above elbow casts needed re-manipulation (Paneru, Rijal et al. 2010). 
Several authors have suggested that surgical treatment is indicated when the fracture is misaligned or unstable (Logan and Lindau 2008, Han, Hong et al. 2014, Liang, Lai et al. 2015, Kim, Kim et al. 2016). Richards et al recommended internal fixation for fractures with more than $50 \%$ displaced and angulation of $10^{\circ}$ or more because this implies disruption of the IOM and thereby longitudinal instability of the forearm (Richards and Deal 2014). Several options may be used for fracture fixation; percutaneous Kirschner wires, interosseous wiring, tension band wiring, screws and plate fixation. The thin soft tissue envelope and the triangular shape of the distal ulna make internal fixation difficult and hardware is poorly tolerated. The volar surface of the bone is considered by some to be the best placement (Kim, Kim et al. 2016). Kirschner wires carry the risk of not providing adequate stability and pin infection. The use of plates is difficult since only 1 or 2 screws usually have room in the distal fragment, and they cannot be bicortical because of the proximity of the DRUJ (Ring, McCarty et al. 2004). With surgical intervention it is also important to be aware of the dorsal sensory branch of the ulnar nerve, which must be identified and preserved (Richards and Deal 2014).
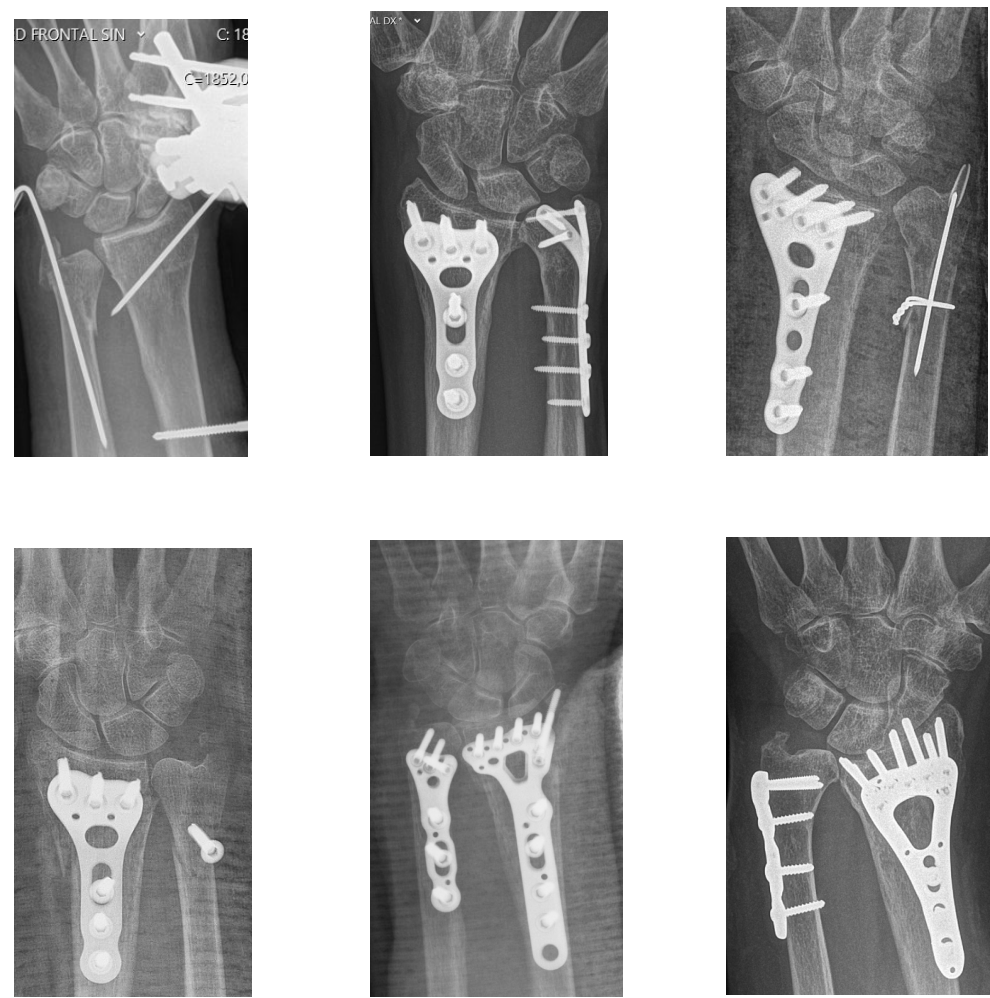

Figure 10. Different methods of internal fixation 
A study on 17 patients operated with an LCP distal ulna plate showed good results after 15 months; all fractures healed, the DRUJ was stable, no ulnar wrist pain, and a DASH score of 11 (Han, Hong et al. 2014). In a study by Ring et al, a minicondylar plate was used for misaligned or unstable distal ulna fractures. Of 24 patients, only one had non-union of the ulna, but seven plates had to be removed because of discomfort from plate prominence, and five patients showed signs of mild osteoarthritis in the radio-carpal joint after 26 months (Ring, McCarty et al. 2004). In a prospective study by Liang et al, they suggested a treatment algorithm where stable radius and ulna fractures were treated with a cast. If reduction was not achieved, the radius fracture was internally fixed and the distal ulna fracture assessed. If the ulna fracture was stable, it was treated conservatively but if unstable it was either internally fixed or resected. In a cohort of 24 patients there was one non-union in the cast group and one delayed union in the group with both bones internally fixed. Based on the GartlandWerley demerit system, most patients in all groups had excellent or good results (Liang, Lai et al. 2015).

In patients 65 years or older, there were no significant differences between conservative and surgical treatment of a distal ulna fracture with a concomitant internally fixed radius fracture regarding DASH score, pain, range of motion, grip strength, modified Gartland and Werley system score or radiological outcome (Cha, Shin et al. 2012). A study on 18 distal ulna fractures in patients 60 years or older showed that all metaphyseal fractures healed with conservative treatment when the radius was fixed with a volar locking plate. Only 10 of the patients had a clinical evaluation and of these, all had an excellent or good result with the modified Gartland and Werley system and a DASH of 4.1 (Sato, Murakami et al. 2018). In a retrospective study on 14 intra-articular distal ulna fractures treated conservatively while the concomitant distal radius fracture was stabilised with a plate, all ulna fractures healed with 11 excellent and 3 good results according to the modified Gartland and Werley system. Five wrists, however, showed radiological signs of osteoarthritis at follow-up after a mean time of 18 months (Namba, Fujiwara et al. 2009).

Özkan and colleagues performed a database study where younger age, open fracture, multi-fragment fractures, and initial open treatment of ulnar neck fractures were shown to be associated with additional unplanned surgery, used as a measure of adverse events of fracture treatment (Ozkan, Fischerauer et al. 2018). A retrospective study on 48 isolated distal ulna fractures showed no difference in healing time regardless of whether the fracture was surgically treated or not. The operated group had more associated injuries and more complications (Williams and Friedrich 2011).

A review by Logan and Lindau in 2008 concluded that there is little scientific support to guide the treatment of distal ulna fractures. They recommended that fractures of the ulnar head with an intra-articular step or that are unstable should be treated with open reduction and internal fixation. This may be achieved by headless compression screws, Kirschner wires, or locked plates. Isolated stable neck fractures or fractures that are stable once the radius is fixed can be treated by immobilisation in 
a cast, whereas irreducible or unstable fractures require open reduction and internal fixation. Here the authors recommended a blade plate, tension band wiring with the addition of intra-fragmentary screws, or a locking plate. For comminuted intra-articular fractures they recommended restoring and maintaining the alignment of the ulna and DRUJ with the option of a salvage procedure later on e.g., head replacement, resection, or soft tissue interposition (Logan and Lindau 2008).

When fixation is considered impossible, salvage procedures include those of Darrach or Sauve-Kapandji or ulnar head replacement (Richards and Deal 2014). In selected cases a salvage procedure might be appropriate as primary management. A retrospective study compared the Darrach procedure with internal fixation in 24 women over the age of 70 years (Boretto, Zaidenberg et al. 2019). They noted more complications in the internal fixation group including ulnar nerve palsy, non-union, plate loosening, infection, complex regional pain syndrome, pain, and restricted motion. However, the patients were not randomised and the Darrach group was significantly older (Boretto, Zaidenberg et al. 2019). Potential complications of surgical treatment of distal ulna fractures include injury or neurapraxia of the dorsal sensory branch of the ulnar nerve, need for hardware removal, and osteoarthritis of the DRUJ. Non-union is not common and reported in 4-11.8\% of cases (Richards and Deal 2014). 


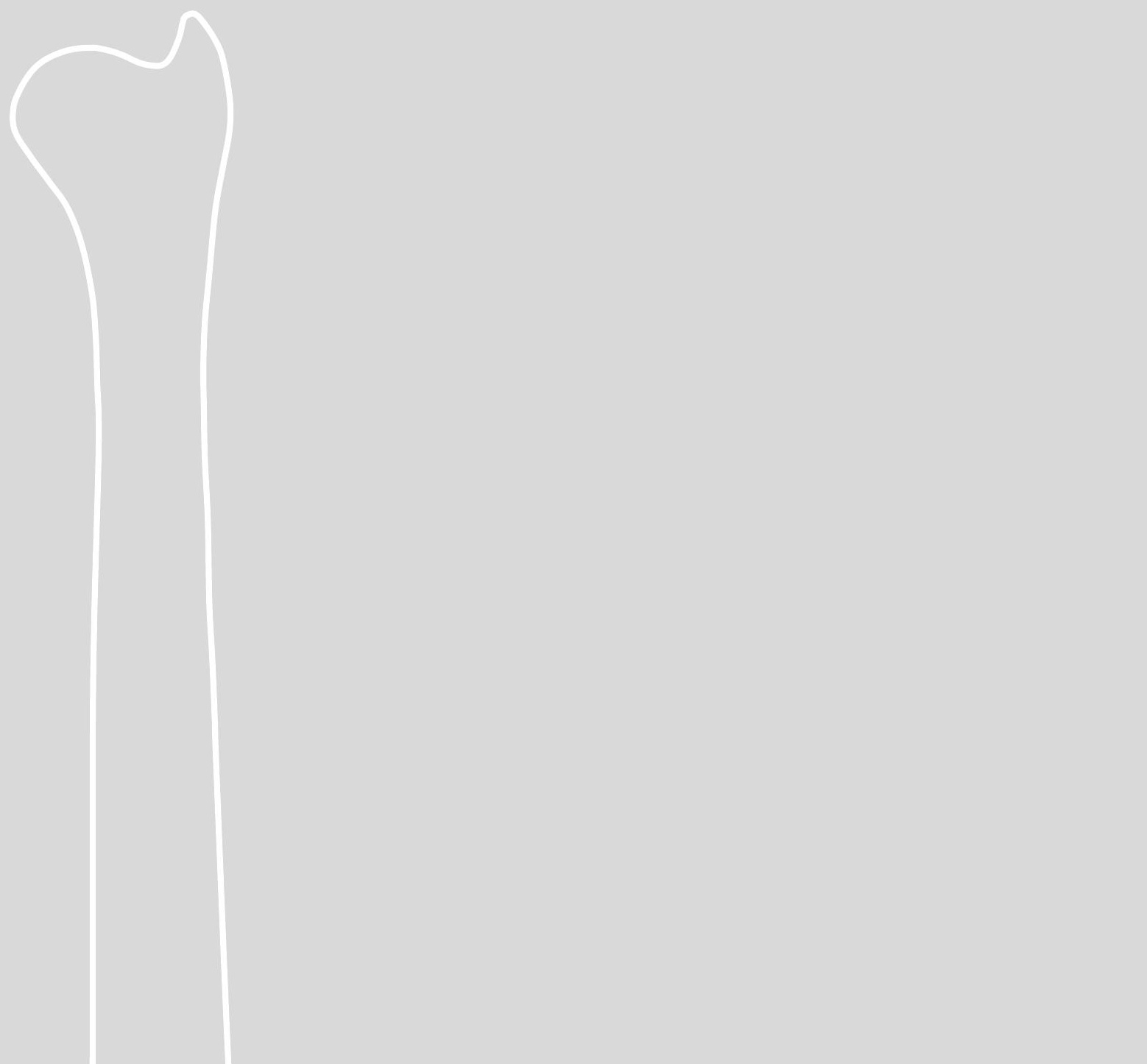




\section{Aims}

The overall aim of this thesis was to evaluate the long-term results of surgical repair of TFCC injuries, and to contribute to our knowledge on fractures of the distal ulna, their epidemiology, radiographic classification, and results of treatment. Specific aims were:

I To investigate functional results and prevalence of osteoarthritis approximately 20 years after foveal TFCC-repair.

II To investigate the incidence of distal ulna fracture in adults and whether any fracture types are more common according to the AO classification, related to type of trauma and demographics. We also wanted to investigate how frequently operative treatment was the treatment of choice related to the various fracture types.

III To investigate outcome of distal ulnar fracture with or without concomitant distal radius fracture, and if the 2018 AO/OTA fracture classification can predict outcome.

IV To compare 3 different radiographic classification systems for distal ulna fractures with regards to reliability and reproducibility. 


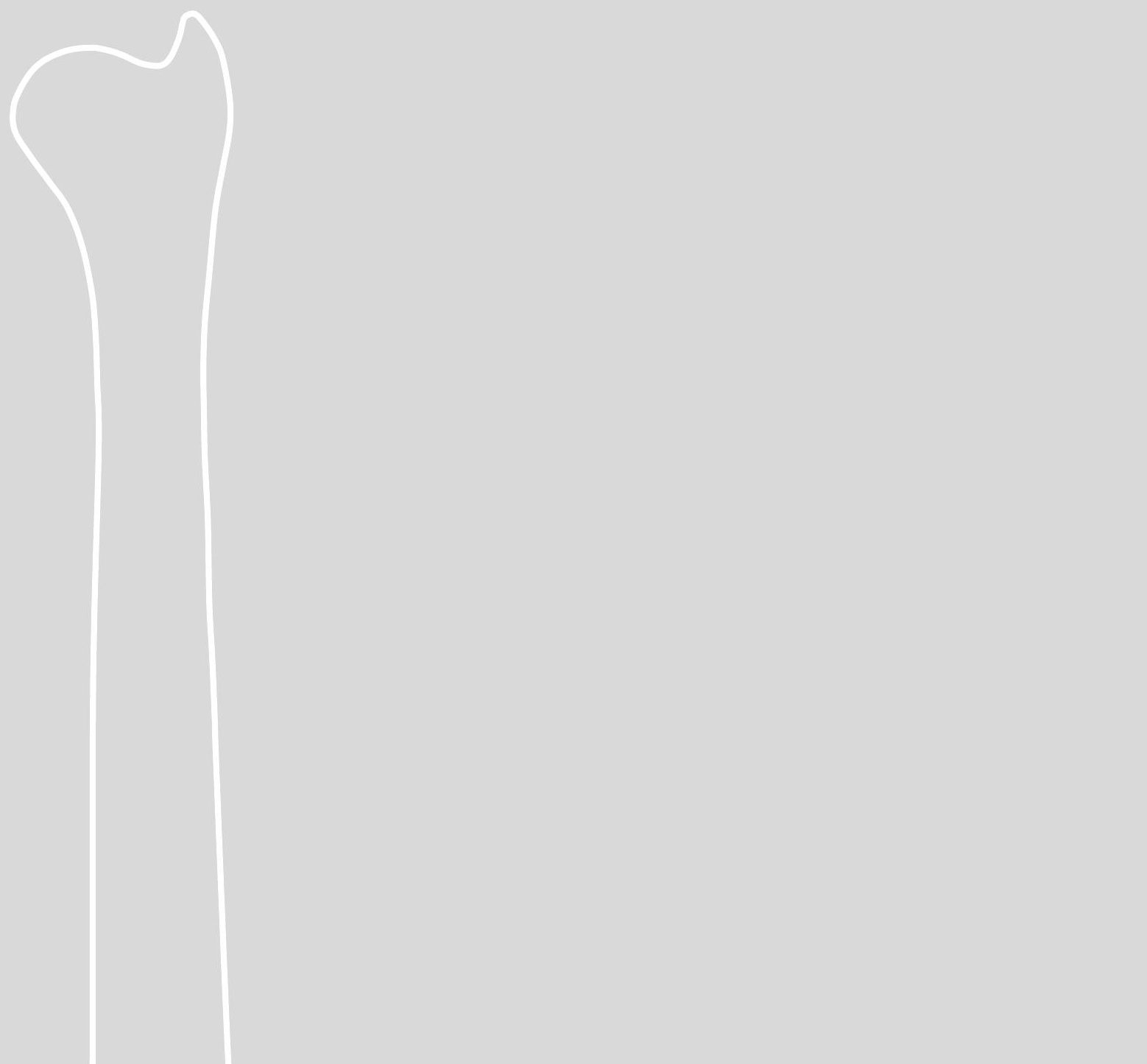




\section{Patients}

Forty-seven patients treated with a TFCC repair at Linköping University Hospital between 1989 and 1999. Inclusion criterion was a repair of a foveal TFCC rupture, Palmer class $1 \mathrm{~B}$, by reinsertion. Patients operated with concomitant procedures were excluded. Mean age was 32 years (SD $14)$, and $62 \%$ were women.

II 766 patients treated for a fracture of the distal ulna, excluding isolated fractures of the ulnar styloid, with or without concomitant fracture of the distal radius. Inclusion criteria were fracture of the distal third of the ulna during 2010-2012, age 18 years or older, and residing in the county of Östergötland, Sweden, at the time of injury. Mean age was 63 years (SD $18)$, and $76 \%$ were women.

III \& IV Ninety-six patients (97 fractures) with a distal ulna fracture treated at the three hospitals in the county of Östergötland 2010-2014. Inclusion criterion was a fracture of the distal third of the ulna. Patients under the age of 18 years or with fracture of the styloid tip only were excluded. Mean age at the time of injury was 63 years (SD 14.5), and $82 \%$ were women. 


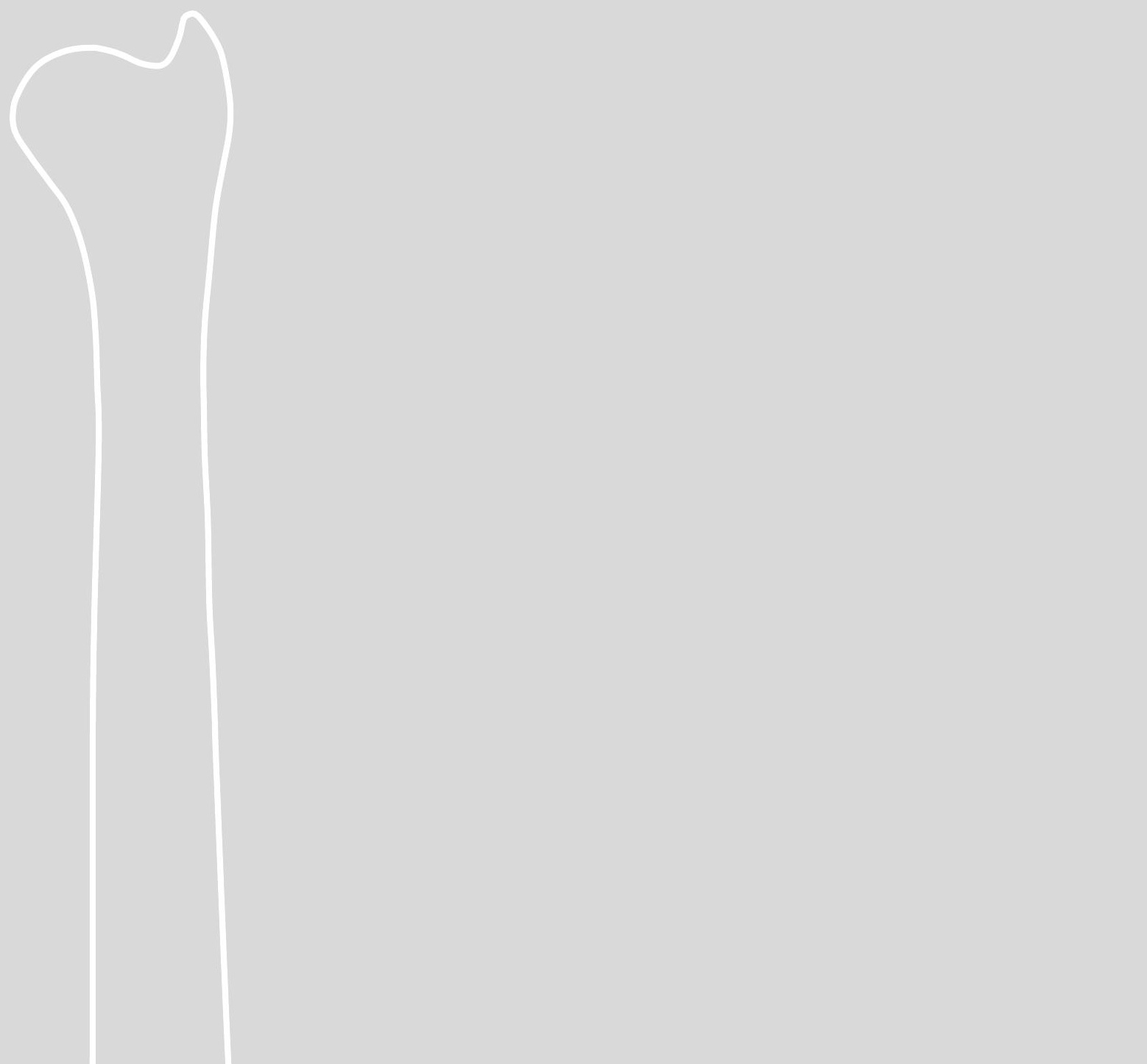




\section{Methods}

\section{Radiography}

Standard radiography was used in all four studies, using standard projections (posteroanterior and lateral). In paper I and III, radiography was used to identify signs of osteoarthritis (OA) in the hand and wrist, and further radiographs of the contralateral wrist were taken for comparison. In paper III, radiographs were also used to identify healing rate, persisting malunion, and ulnar variance. In paper II, III and IV radiographs were used for fracture classification.

\section{PRWE}

Pathology of the wrist has traditionally been examined and assessed using objective measures as radiography, range of motion, and grip strength. Patient-reported outcome measures have become increasingly important, adding further information to these objective measures. Outcome measures should assess severity and document clinical changes over time. General health or quality-of-life measures such as SF-36 and sickness impact profile, are adequate for a variety of conditions, but are not designed for conditions of the wrist and are not ideal tools for evaluating wrist interventions. In 1998 the Patient Rated Wrist Evaluation (PRWE) questionnaire was developed by MacDermid et al. It was developed to be wrist-specific and easy to use by both patient and practitioner. PRWE comprises 15 questions divided into two equally weighted subscales evaluating both pain and function. The total score ranges from 0 (perfect wrist) to 100 (completely disabled and painful wrist) with 50 points from each subscale. The pain subscale contains 5 items and the function subscale 10 items. Each item is scored between 1 and 10 . The pain score is the sum of all items while the function score is the sum divided by two. When developing the questionnaire it was shown that the correlation between objective measures and patient-reported pain and disability were only moderate, indicating that factors other than those traditionally measured play a role for patient perception of the result (MacDermid, Turgeon et al. 1998). PRWE has been translated into and validated in Swedish by two different research groups (Wilcke, Abbaszadegan et al. 2009, Mellstrand Navarro, Ponzer et al. 2011). We have chosen to use the translation of Mellstrand-Navarro et al because their translation of the question concerning forced pronation and supination was more relevant to our research. Compared to the Disability of the Arm, Shoulder, and Hand (DASH) and Short Form-36 (SF-36) questionnaires, PRWE was found to be the most responsive when analysing a cohort of patients with distal radius fracture, followed by DASH. This demonstrates that wrist-specific questionnaires are more responsive in detecting clinical changes (MacDermid, Richards et al. 2000). Changulani et al concluded that DASH is the best score for evaluating disorders involving multiple upper limb 
articulations, while PRWE is a validated tool more suited to distal radius fractures (Changulani, Okonkwo et al. 2008).

When PRWE is used to evaluate treatment outcome, it is important to define what is the minimum clinically important difference (MCID) and the minimum detectable change (MDC). The MCID represents the smallest change in score that the patient can recognize as important change, while the MDC is the smallest change an outcome measure can detect beyond measurement error. In a study of patients with a distal radius fracture, the MCID of PRWE was found to be 11.5 points and the MDC 11 points (Walenkamp, de Muinck Keizer et al. 2015). Other studies have reported MCIDs between 14 and 24 points (Schmitt and Di Fabio 2004, Sorensen, Howard et al. 2013) and MCDs between 7.7 and 12.2 (Schmitt and Di Fabio 2004, Kim and Park 2013). The population-based normative data have a median PRWE score of 0 (IQR: 0-8.5) and a mean score of 7.7 (SD 15.0). The scores are significantly higher in women and older patients, this being associated with function rather than pain (Mulders, Kleipool et al. 2018).

In a review from 2012, PRWE was reported to have favourable validity, reliability, and responsiveness (McPhail, Bagraith et al. 2012). Another review concluded that of the different PROMs used for hand and wrist trauma, only PRWE and DASH have evidence of reliability, validity and responsiveness. PRWE has by far the best demonstrated reliability and validity in wrist trauma (Dacombe, Amirfeyz et al. 2016). 


\section{Fracture classification systems}

Classifications of fractures are used for both clinical and research purposes. For a classification to be clinically relevant and routinely used, it should preferably have some impact on outcome or help guide the clinician when choosing the best treatment for a specific fracture. An accurate classification should be reliable and reproducible. The most well-known and extensive classification is that developed by Müller and coworkers in 1990 (Müller M.E. 1990). This was the basis on which the Arbeitsgemeinschaft für Osteosynthesefragen (AO) Foundation/ Orthopaedic Trauma Association (OTA) classified the remaining bones and published a compendium in the Journal of Orthopaedic Trauma 1996. In the original AO classification, distal ulna fractures associated with distal radius fractures were classified with a $Q$ modifier. There were 6 different Q classes of which Q1 referred to a styloid fracture (Müller M.E. 1990).

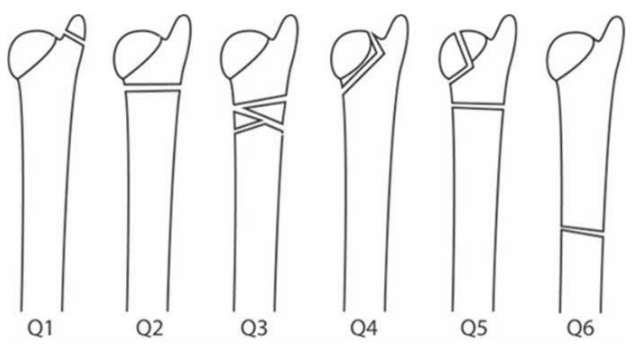

Figure 11. AO/OTA 2007

The AO and OTA classification committee revised the classification in 2007 and 2018. By the latest review it had become evident that it was more accurate to code radius and ulna fractures separately. The distal segment of ulna is now classified as $2 \mathrm{U} 3$ followed by $A$ for extra-articular, B for partial articular, and $C$ for complete articular fractures. 2U3A was further subdivided into 1 for styloid process (subdivided into (1) Tip and (2) Base), 2 for simple (subdivided into (1) Spiral, (2) Oblique, and (3) Transverse) and 3 for multi-fragmentary. This means that there are 8 possible classes of distal ulna fracture. There are also universal modifiers that can be added to the end of the fracture code, for example, impaction or dislocation (Meinberg, Agel et al. 2018).

The Biyani classification was developed in 1995 for concomitant fractures of the distal radius and ulnar metaphysis, with or without associated fractures of the ulnar styloid. This was based on a radiographic review of 19 fractures of the distal radius and ulna. It showed four different fracture patterns, namely Types 1-4 (Biyani, Simison et al. 1995). Type 1 - simple extra-articular fracture, Type 2 - inverted T or Yshaped fracture with a styloid fragment including part of the metaphysis, Type 3 transverse fracture of the ulnar neck combined with fracture of the styloid, and Type 4 - comminuted fracture of the metaphysis with or without styloid fracture. 


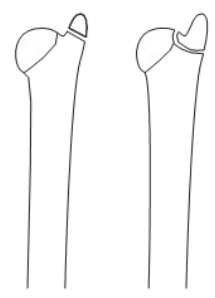

2U3A1.1 2U3A1.2

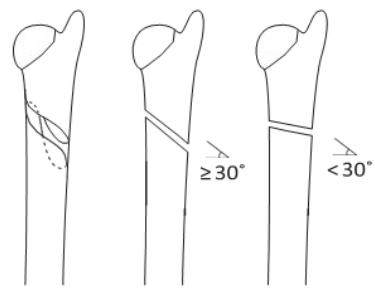

$\begin{array}{lll}2 U 3 A 2.1 & \text { 2U3A2.2 } & 2 U 3 A 2.3\end{array}$

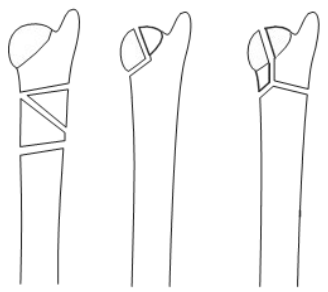

2U3A3 2U3B 2U3C

Figure 12. AO/OTA 2018

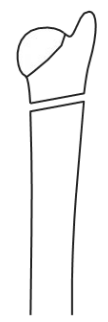

1

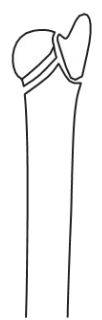

2

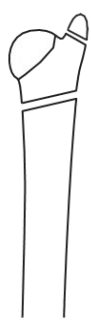

3

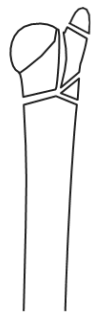

4

Figure 13. The classification of Biyani et al

52 


\section{Statistical tests}

In paper I, statistical analysis of PRWE scores was done using the Mann-Whitney Utest. For categorical values, the two-tailed Fisher test was used. Logistic regression was used to correct for age and gender. In paper III, the non-parametric SPSS Median test was used to compare median values, and the Chi2-test to compare other variables. In paper IV, Kappa value analysis was used to determine inter- and intra-rater agreement. In all papers a $p$-value $<0.05$ was considered statistically significant.

\section{Data collection and assessment}

In paper I, patients who had been operated with a foveal TFCC repair between May 1989 and June 1999 were identified through the hospital's internal database, and medical records were used to identify symptoms, type of trauma, diagnostic methods, and treatment. In paper II, III and IV adult patients with a distal ulna fracture treated in the county of Östergötland, Sweden, were identified through the patient register of Östergötland. The register was searched for all ICD-10 codes for distal forearm fracture (S52.50, S52.51, S52.60, S52.61, S52.20, S52.21, S52.80, S52.81). The radiographs of all patients with one of these codes were then screened in the digital radiology system to identify patients who had had a fracture of the distal third of the ulna. The type of trauma and the chosen treatment were recorded using the radiography referrals and subsequent radiographs.

\section{Paper I}

Patients operated with a reinsertion of a foveal TFCC rupture between 1989 and 1999 were included and evaluated approximately 20 years after surgery (SD 2, range 15-25 years). The primary outcome measure was PRWE score, and new radiographs were taken to identify signs of osteoarthritis in the wrist.

\section{Paper II}

All patients aged 18 years or older, treated for a fracture of the distal third of ulna in the county of Östergötland, Sweden, 2010-2012, were included. Type of trauma and treatment given were recorded. All fractures, excluding styloid fractures, were classified according to the AO/OTA 2007 classification by a senior radiologist. Reliability was examined by a second radiologist classifying twenty randomly chosen fractures. Incidence was calculated using the population size according to Statistics Sweden (SCB). 


\section{Paper III}

Patients aged 18 years or older treated for fracture of the distal third of ulna in the county of Östergötland, Sweden, 2010-2014, were included. Patients with fracture of the styloid tip were excluded. Two radiology specialists independently classified the fractures according to the AO/OTA 2018 classification, and disagreement was solved through consensus discussion. Follow-up was performed 5-7 years after the injury using PRWE, and new radiographs taken of the injured wrist and the contralateral side for comparison. The radiographs were used to identify signs of osteoarthritis, healing rate, remaining malunion, and ulnar variance.

\section{Paper IV}

Fractures of the distal third of the ulna in adults, excluding isolated fractures of the styloid tip, were individually classified by 3 observers: two senior radiology consultants and one senior orthopaedic consultant. Classification was performed according to the classification of Biyani et al, AO/OTA 2007, and AO/OTA 2018 using the initial radiographs used for diagnosing the fractures. Classification was repeated after a minimum of 3 weeks. Reliability and reproducibility were determined for the three classification systems. 


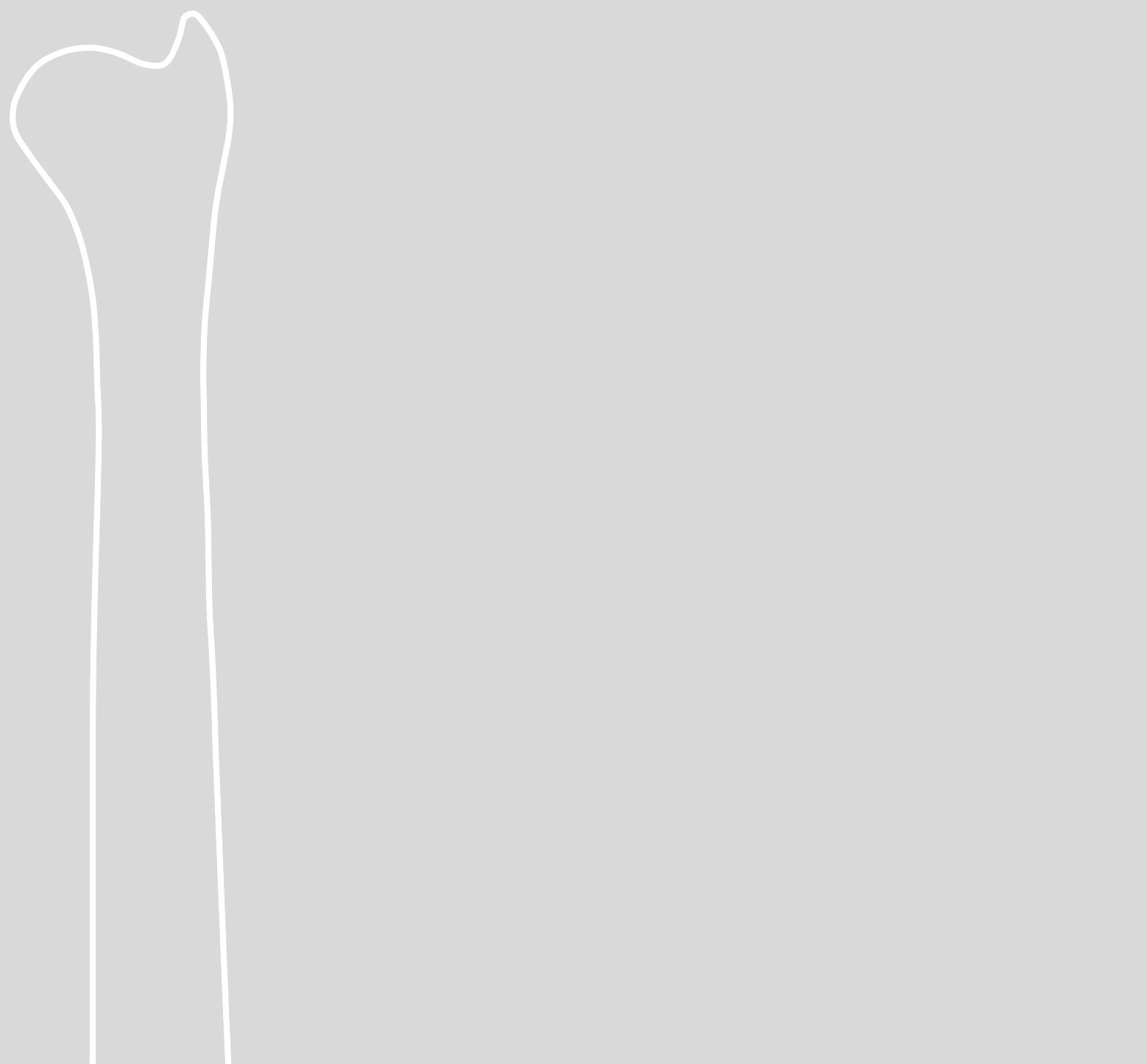




\section{Review of the papers and main results}

\section{Paper I}

We evaluated long-term functional outcome after TFCC repair. Forty-seven patients answered the PRWE questionnaire 15-25 years after open repair of a foveal TFCC tear. Forty-three patients also had radiographs taken at least 10 years after surgery. All patients were judged to have a stable DRUJ 3 months postoperatively. Sixteen of the patients (34 \%) eventually underwent additional surgery of the same wrist, eight (17\%) due to recurrent symptoms ascribed to DRUJ instability and considered as reoperations. The median PRWE score was 22.5 (7-48.5). $17.5 \%$ of patients had developed signs of OA in the radio-carpal joint and $34 \%$ in the DRUJ. Patients with OA had a significantly higher pain score of PRWE $(p=.044)$. Patients who had additional surgery also had a significantly higher PRWE score $(p=.0003)$. Significantly fewer of the patient who underwent wrist arthroscopy at primary surgery had developed radiocarpal OA $(p=.036)$. Concomitant distal radius fracture was associated with development of OA of the DRUJ $(p=.015)$.

\begin{tabular}{lrrr} 
PRWE, median (Q1-Q3) & Pain & Function & Total \\
\hline All $(n=47)$ & $15(6-29)$ & $9.5(1.5-20)$ & $22.5(7-48.5)$ \\
Radiocarpal osteoarthritis $(n=7)$ & $29(18-34)^{*}$ & $21.5(2-33.5)$ & $52.5(20-67.5)^{*}$ \\
No radiocarpal osteoarthritis $(n=33)$ & $11(6-22)$ & $6(1.5-14)$ & $17(7-38)$ \\
DRUJ osteoarthritis $(n=18)$ & $16.5(6-29)$ & $7.75(1-21.5)$ & $23.25(6.5-52.5)$ \\
No DRUJ osteoarthritis $(n=23)$ & $13(6-27)$ & $7.5(1.5-15)$ & $22.5(7.5-44)$ \\
Additional surgery $(n=16)$ & $30(18.5-34)^{*}$ & $20.75(11.75-25.5)^{*}$ & $47.75(34.75-56.5)^{*}$ \\
No additional surgery $(n=31)$ & $11(4-19)$ & $3(1-11.5)$ & $14(5-27.5)$ \\
\hline
\end{tabular}

* Indicates $\mathrm{p}<0.05$

Table 3. Results of the PRWE questionnaire

\section{Paper II}

We identified 766 distal ulna fractures in the county of Östergötland 2010-2012, giving an annual incidence of 74/100 000 person-years. Most common were fractures of the ulnar styloid (79 \%) followed by fractures of the ulnar neck (11\%). The radiologists agreed on the classification in $70 \%$ of the fractures, and disagreement was usually due to lack of landmarks defining the different fracture classes. Mean age at the time of injury was 63 years (SD 18), $76 \%$ were women, and $92 \%$ had a concomitant fracture of the radius ( $98 \%$ in the group with a styloid fracture). The main type of trauma was a fall from standing height. High-energy trauma was more common in younger patients, and $30 \%$ of Q2-Q6 fractures were treated with internal fixation. 


\begin{tabular}{lrr} 
Fracture class & Amount, $\mathbf{n}(\%)$ & Incidence (/100,000 person-years) \\
\hline Q1 & $607(79)$ & 59 \\
Q2 & $83(11)$ & 8 \\
Q3 & $28(4)$ & 3 \\
Q4 & $5(1)$ & 1 \\
Q5 & $16(2)$ & 2 \\
Q6 & $27(4)$ & 3 \\
All & 766 & 74 \\
\hline
\end{tabular}

Table 4. Incidence according to AO/OTA 2007 classification

\section{Paper III}

Patient-reported outcome of distal ulna fracture (excluding the styloid) was measured using PRWE in a cohort of 96 patients (97 fractures) 5-7 years after injury. New radiographs were taken of 66 of the fractured wrists (65 patients). All fractures did not fit perfectly into the radiographic AO/OTA 2018 classification, and $31 \%$ needed consensus discussion for classification. Extra-articular transverse fracture (2U3A2.3) was the most common, 22 patients had an isolated ulna fracture, $40 \%$ were treated by internal fixation, 2 fractures (3\%) never healed, and $20 \%$ had residual displacement. Signs of osteoarthritis in the DRUJ were seen in $33 \%$, and $55 \%$ had signs of osteoarthritis somewhere in the radio-carpal, intercarpal or carpo-metacarpal joints. The median PRWE was 15 (IQR 33.5) with scores being significantly higher in patients with operated distal ulna fractures $(p=.01)$. When relating this to the AO/OTA 2018 classification, a significant difference in favour of non-operated fractures was seen in class 2U3A2.3 $(p=.001)$. Extra-articular transverse fractures were operated more frequently if there was initial displacement $(p=.012)$ but the displacement was not significantly associated with PRWE score. Patients who developed osteoarthritis had worse PRWE scores $(p=.017)$. At follow-up, ulna fractures that had been treated surgically more frequently showed signs of osteoarthritis somewhere in the wrist $(p=.047)$. 


\begin{tabular}{lrrrr} 
& $\begin{array}{r}2 \text { U3A2.2 } \\
\text { Extra-articular } \\
\text { oblique }\left(\geq 30^{\circ}\right)\end{array}$ & $\begin{array}{r}\text { 2U3A2.3 } \\
\text { Extra-articular } \\
\text { transverse }\left(<30^{\circ}\right)\end{array}$ & $\begin{array}{r}\text { 2U3A3 } \\
\text { Eultifragmentary }\end{array}$ & $\begin{array}{r}\text { 2U3C } \\
\text { Complete } \\
\text { articular }\end{array}$ \\
\hline Amount & 24 & 41 & 13 & 17 \\
Mean age, years(SD) & $62(13)$ & $64(16)$ & $65(18)$ & $63(11)$ \\
Isolated & $7(29 \%)$ & $8(20 \%)$ & $6(46 \%)$ & 0 \\
Ulna operated & $(3$ operated) & $(2$ operated) & $(2$ operated) & $5(29 \%)$ \\
Only radius operated & $11(46 \%)$ & $16(39 \%)$ & $7(54 \%)$ & $7(41 \%)$ \\
Not operated at all & $9(38 \%)$ & $13(32 \%)$ & 0 & $5(29 \%)$ \\
Follow-up radiographs & $4(17 \%)$ & $12(29 \%)$ & $6(46 \%)$ & 11 \\
Healed & 16 & 30 & $7(100 \%)$ & $11(100 \%)$ \\
Remaining displacement & $15(94 \%)$ & $29(97 \%)$ & $1(14 \%)$ & $2(18 \%)$ \\
Osteoarthritis DRUJ & $2(13 \%)$ & $8(27 \%)$ & 0 & $2(18 \%)$ \\
Any carpal or DRUJ osteoarthritis & $5(31 \%)$ & $15(50 \%)$ & $1(14 \%)$ & $5(45 \%)$ \\
Ulnaminus & $9(56 \%)$ & $21(70 \%)$ & $2(29 \%)$ & $3(27 \%)$ \\
PRWE total & $4(25 \%)$ & $4(13 \%)$ & $6(34.3)$ & $17.5(33)$ \\
PRWE pain & $9.3(30.3)$ & $19(36.8)$ & $4(20)$ & $10(22)$ \\
PRWE function & $5(16)$ & $10(22)$ & $2(16.8)$ & $6.5(12.5)$ \\
PRWE Ulna operated & $5.8(17.5)$ & $7.5(20.5)$ & $7(54)(\mathrm{n}=7)$ & $17.5(35.5)(\mathrm{n}=5)$ \\
PRWE Ulna not operated & $21.5(60)(\mathrm{n}=11)$ & $33(27.3)(\mathrm{n}=16)^{*}$ & $1.5(28.1)(\mathrm{n}=6) 13.5(31.6)(\mathrm{n}=12)$
\end{tabular}

* indicates a significant difference with $p<.05$

Table 5. Demographics and results according to fracture class. In the table one fracture of 2U3A1.2 and one of 2U3A2.1 are excluded.

\section{Paper IV}

Three independent observers classified 97 fractures of the distal ulna (excluding the ulnar styloid) according to the classifications of Biyani et al, AO/OTA 2007 and AO/OTA 2018. The classification was repeated after a minimum of three weeks. When assessing the reliability the total mean $\mathrm{k}$ value of the AO/OTA 2007 classification was judged as fair ( $\mathrm{k}$ 0.396), whereas $\mathrm{k}$-values for AO/OTA 2018 and Biyani were judged as moderate ( $\mathrm{k} 0.424$ and 0.427 respectively). The reproducibility (intra-rater agreement) was moderate for all classifications: fair for observer 1, moderate for observer 2 and substantial for observer 3 .

\begin{tabular}{llll} 
AO/OTA 2007 & Observers Kappa & Judgement \\
\hline First examination & 1 vs 2 & 0.545 & Moderate agreement \\
& 1 vs 3 & 0.315 & Fair agreement \\
& 2 vs 3 & 0.389 & Fair agreement \\
& Mean & 0.416 & Moderate agreement \\
Second examination & 1 vs 2 & 0.426 & Moderate agreement \\
& 1 vs 3 & 0.259 & Fair agreement \\
& 2 vs 3 & 0.445 & Moderate agreement \\
& Mean & 0.376 & Fair agreement \\
Total & Mean & 0.396 & Fair agreement \\
\hline
\end{tabular}

Table 6. Reliability of AO/OTA 2007

\begin{tabular}{llll} 
AO/OTA 2018 & Observers Kappa & Judgement \\
\hline First examination & 1 vs 2 & 0.537 & Moderate agreement \\
& 1 vs 3 & 0.356 & Fair agreement \\
& 2 vs 3 & 0.353 & Fair agreement \\
& Mean & 0.415 & Moderate agreement \\
Second examination & 1 vs 2 & 0.458 & Moderate agreement \\
& 1 vs 3 & 0.437 & Moderate agreement \\
& 2 vs 3 & 0.404 & Fair agreement \\
& Mean & 0.433 & Moderate agreement \\
Total & Mean & 0.424 & Moderate agreement \\
\hline
\end{tabular}

Table 7. Reliability of AO/OTA 2018 


\begin{tabular}{llll} 
Biyani & Observers Kappa & Judgement \\
\hline First examination & 1 vs 2 & 0.507 & Moderate agreement \\
& 1 vs 3 & 0.430 & Moderate agreement \\
& 2 vs 3 & 0.507 & Moderate agreement \\
& Mean & 0.493 & Moderate agreement \\
Second examination & 1 vs 2 & 0.300 & Fair agreement \\
& 1 vs 3 & 0.253 & Fair agreement \\
& 2 vs 3 & 0.531 & Moderate agreement \\
& Mean & 0.361 & Fair agreement \\
Total & Mean & 0.427 & Moderate agreement \\
\hline
\end{tabular}

Table 8. Reliability of the classification of Biyani

\begin{tabular}{llll} 
Classification system & Observer & Kappa & Judgement \\
\hline AO/OTA 2007 & 1 & 0.284 & Fair agreement \\
& 2 & 0.648 & Substantial agreement \\
& 3 & 0.649 & Substantial agreement \\
AO/OTA 2018 & Mean & 0.527 & Moderate agreement \\
& 1 & 0.375 & Fair agreement \\
& 2 & 0.515 & Moderate agreement \\
& 3 & 0.662 & Substantial agreement \\
Biyani & Mean & 0.517 & Moderate agreement \\
& 1 & 0.417 & Moderate agreement \\
& 2 & 0.641 & Substantial agreement \\
& 3 & 0.684 & Substantial agreement \\
& Mean & 0.581 & Moderate agreement \\
\hline
\end{tabular}

Table 9. Reproducibility of the classification systems

The three classifications were found to be lacking in several aspects. Several of the fracture types found in our material were not included in the two AO classifications, and to a lesser degree this was also the case with the Biyani classification. The Biyani classification was also found to be very distal, not comprising the whole distal third of the ulna. However, according to the observers Biyani was judged as the classification easiest to apply. Plain radiographs were used for the classification, making it difficult to decide whether or not the fracture system was extra- or intra-articular. A CT, for example a $\mathrm{CBCT}$, which provides more information about the extensions of the fracture system would make this easier to identify and could improve the accuracy of classification. 


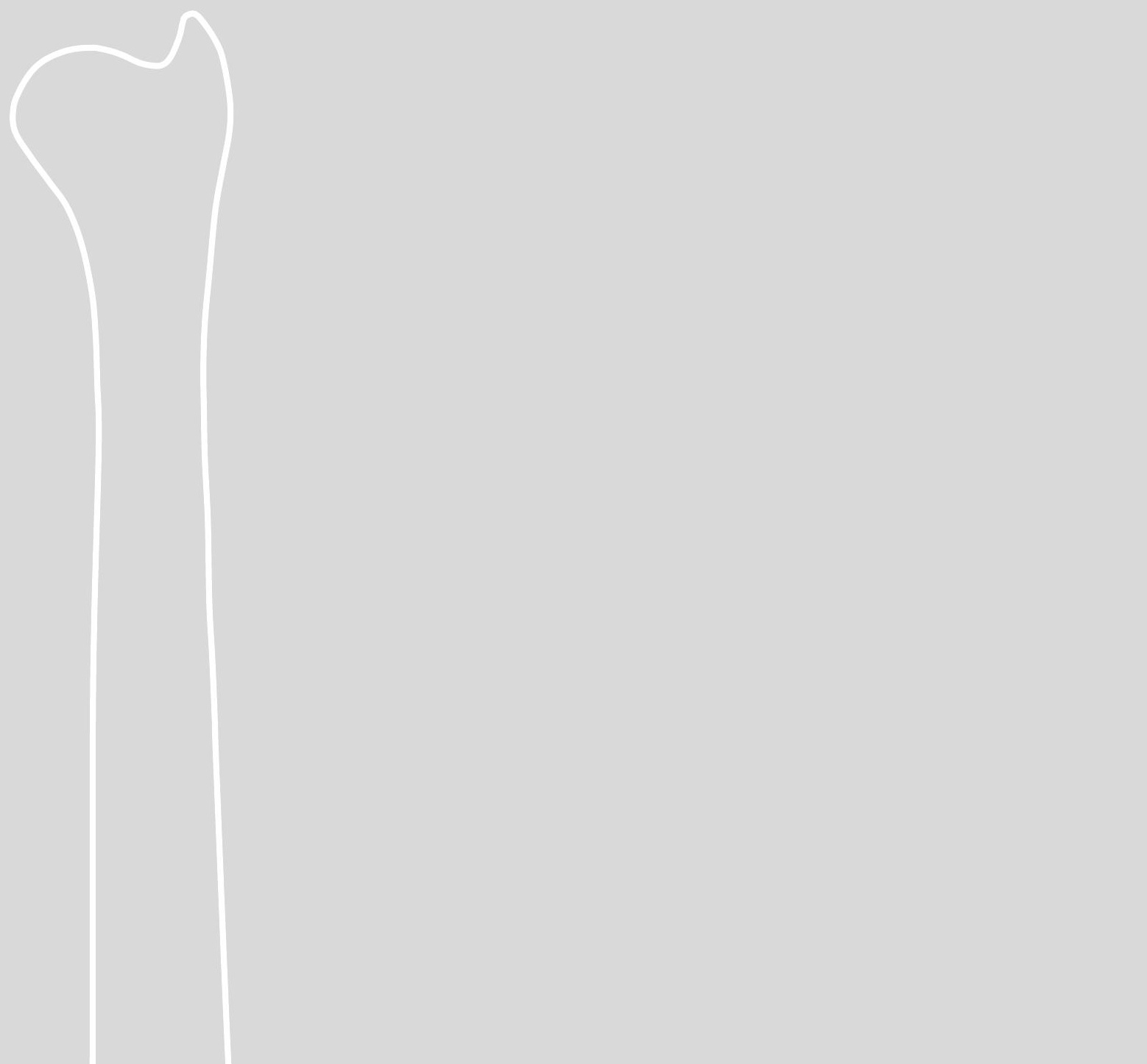




\section{Discussion}

\section{Is a TFCC repair really worth it in the long run?}

In paper I, the patient-reported outcome of PRWE at long-term follow-up after open TFCC repair (22.5) was comparable to the outcome of distal radius fracture. Since many TFCC injuries are associated with a distal radius fracture, this result seems adequate, but there is still room for improvement. When comparing studies it is important to know the characteristics of the populations investigated; acute or delayed repair, concomitant injuries, type of tear and type of repair used. Other studies on TFCC repair have shown PRWE scores of between 5 and 19.5 (Selles, d'Ailly et al. 2020, Thalhammer, Haider et al. 2021), where better results were achieved in a population with very strict exclusion criteria and with no reoperations (Thalhammer, Haider et al. 2021). After trauma, duration of symptoms before surgery probably has an impact on outcome. In our study, the duration of symptoms before surgery was on average 1 year indicating that many of these injuries are initially missed, or misdiagnosed, that other treatments may have failed, or that there was considerable time waiting for surgery. Through better knowledge and high degree of suspicion among surgeons managing acute wrist trauma, and through easy access to arthroscopy when injuries are suspected clinically, more of these patients will be diagnosed at an earlier stage.

Several of our patients (34\%) needed additional surgery; half of them due to reoccurrence of DRUJ instability, but the remaining half needing other procedures. This indicates that surgery is required for associated injuries at a later stage. Falling on an outstretched hand is a very common incident that leads to a multitude of injuries. Some of these are easy to diagnose immediately (fractures), some become apparent after a period with of symptoms (instability due to ligament injuries), while some symptoms arise a long time after injury (cartilage injuries leading to the development of OA). The fact that about $50 \%$ of our patients did not have arthroscopy at the initial operation could be the reason why associated injuries were missed in this group and were thus not treated adequately. The actual reoperation frequency due to DRUJ instability was $17 \%$. Other studies have also reported that reoperation is not uncommon after TFCC repair. Anderson et al also reported that $17 \%$ of their patients were reoperated because of recurrent DRUJ instability, this being significantly associated with female gender (Anderson, Larson et al. 2008). They also compared open versus arthroscopic repair of peripheral TFCC tears and could not find any difference in clinical outcome. In another study on arthroscopically repaired TFCC tears, $29 \%$ were reoperated, mainly because of persisting wrist pain (Estrella, Hung et al. 2007).

In another long-term follow up of 11 patients undergoing arthroscopically assisted TFCC repair, results were similar to ours, with a PRWE score of 17 (Soreide, Husby et al. 2017). Their patients also had a long duration of symptoms before treatment, and two patients were reoperated before follow-up. Since both this study and ours are long-term follow-ups, surgery primarily took place during the 90 s when 
patients suffering from DRUJ instability were usually assigned a Palmer 1B lesion. However, at the time, not many other causes of DRUJ instability were diagnosed and treated, which could have influenced the outcome and explain why additional surgery was required in some cases (Soreide, Husby et al. 2017).

A problem with all long-term follow-up studies is that a great deal can change during that time. Questionnaires are revised, implants change, and equipment improves. For example, the development of arthroscopy equipment has made arthroscopy easier and we can obtain more information about the anatomy. Today the value of arthroscopy is undeniable. So how valuable are the findings of our long-term follow-up study? Foveal TFCC repair today is fairly similar to that performed 20 years ago, so we believe this study contributes to our knowledge on how results withstand over time. In a follow-up study on acute TFCC injuries associated with a distal radius fracture, it could not be shown that they would influence long-term outcome (Mrkonjic, Geijer et al. 2012). This is probably true on a group level, but for tears leading to symptomatic instability of the DRUJ, a repair can reduce the patient's symptoms and result in better wrist function. If it was possible to identify and treat such patients at an early stage there may well be both short- and long-term gains, but how to achieve that has yet to be determined. Maybe a standardised examination of DRUJ stability in all patients with a distal radius fracture at the time of mobilisation after cast treatment, or during surgery after fixation of the radius would make it possible to identify more TFCC injuries and treat them correctly. Recent improvements in the treatment of distal radius fracture with shorter immobilisation time also raises the question whether this has an impact on concomitant TFCC injuries.

Arthroscopy is important in identifying the cause of ulnar-sided wrist pain. In paper I, we observed that patients with a previous TFCC repair where arthroscopy was included less frequently showed signs of radio-carpal OA. It is possible that arthroscopy made it possible to identify other associated injuries and to properly classify the TFCC injury, thus making choice of treatment suitable. Most hand surgeons of today agree on the value of arthroscopy, and that it should always be performed in patients with DRUJ instability as an aid to diagnosis and treatment. Our findings support this view.

\section{Do distal ulna fractures warrant more attention?}

Distal ulna fractures are not common, but when they occur they are often accompanied by a distal radius fracture or other injuries caused by falling onto an outstretched arm with the wrist extended. In paper II we found that in most cases distal ulna fractures heal without internal fixation, and in cases where internal fixation is performed, complications are relatively common based on the patient-reported outcome. We concluded that transverse extra-articular fractures (the most common type of distal ulna fracture after styloid fracture) if treated conservatively, heal with better functional results. Transverse fractures probably heal well because of soft tissue stabilisers such as the TFCC and distal oblique bundle (DOB). When these are intact, 
they stabilise the fracture area once the radius has been reduced and is stable. A large contact area between the two fragments is also beneficial for stability and healing of the fracture.

Other fracture types are so rare that it would require a large multicentre trial to prove whether they should receive internal fixation or not. Some fracture types probably benefit from internal fixation, but to identify these is difficult because of the low incidence of distal ulna fracture and some subgroups in particular. In the field of hand surgery it is not uncommon with eminence based papers expressing surgeons' opinions or small case series, and this is also the case with many papers regarding distal ulna fractures. This is something we want to avoid, and that the surgeon's experience or believes should not be the only thing determining treatment. With a large multicentre study it is possible to gather more of the rare fracture types, making it easier to determine when surgery should be chosen or not. With more detailed diagnostics and a better classification it might be possible to identify fracture types that benefit from surgery.

The possibility of residual symptoms from misalignment or non-union after conservative treatment must be compared with the complications that may arise after internal fixation. Obviously, the functional outcome of distal ulna fracture treatment will be influenced by the result of treatment of an associated distal radius fracture. Isolated distal ulna fractures usually occur after high energy trauma or a direct blow to the forearm and in a completely different population of patients who are younger and have greater demands regarding hand function (Williams and Friedrich 2011). Fractures with intra-articular step-off, displacement, and multifragmentation could well benefit from internal fixation, but this has yet to be shown. Improving the treatment of distal ulna fractures could result in better functional outcome and reduce the number of patients with residual ulnar sided wrist pain. A general understanding of distal ulna fractures is important to choose the optimal treatment and avoid unnecessary complications. So yes, distal ulna fractures deserve more attention and more knowledge needs to be gathered for optimal treatment and outcome.

\section{Why should we bother with classifications?}

A classification, must have clinical relevance if it is to be used. Current classifications of TFCC injuries help guide the surgeon in choice of treatment. When it comes to classifications of distal ulna fractures, however, this aspect has not been taken into account. The old and new AO classification systems were designed according to classifications of other long bones and not related to how the ulna is commonly fractured. Even though current distal ulna fracture classifications are not very good, I still believe that a better classification would be clinically valuable, especially when it comes to uncommon fractures. A distal ulna fracture classification with high accuracy, reliability, and reproducibility, would certainly be a useful aid for the surgeon when choosing the most appropriate treatment. A treatment algorithm based on the fracture's appearance would not only make treatment decisions easier, but also 
enable equal treatment for all patients regardless of hospital or surgeon they attend, a great step towards improving results.

Plain radiographs may not be sufficient to accurately classify distal ulna fractures. More information is provided by CT. Cone beam CT (CBCT), originally used in orthodontics, has recently received attention for use in wrist trauma diagnostics. CBCT has a higher spatial resolution than conventional CT and utilizes lower radiation dose, comparable to that of 2-3 plain radiographs (Pallaver and Honigmann 2019). As many as $50.4 \%$ of patients who still suffered from wrist pain after 1-2 weeks immobilisation, and in whom initial radiographs did not identify a fracture, had a fracture in the wrist identified by CBCT (Gibney, Smith et al. 2019). CBCT as standard investigation in wrist trauma would identify more fractures accurately and better depict distal ulna fractures. Intra-articular fractures, in particular, would be easier to visualise with CBCT, since 2-dimensional images provided by standard radiography easily miss this involvement. We believe that in this patient group there may well be fracture types that gain from internal fixation, but identification of these must be improved and a more accurate classification would help to achieve this. When developing new radiographic standards it is important to recognise that existing treatment algorithms and evaluation measurements have been based on standard radiographs. In distal radius fractures, for instance, $\mathrm{CT}$ scanning is reliable when measuring dorsal tilt, carpal alignment, radial inclination, and ulnar variance. With the dorsal tilt, however, there is a risk of measurements not being comparable with standard radiographs if the CT reconstruction planes are not completely perpendicular to the longitudinal axis of the forearm (Kramer, Selles et al. 2021).

A new classification system is needed that is slightly more extensive than the Biyani but with fewer subgroups than AO/OTA 2018. A clinically relevant classification should include most of the fracture types usually seen, but when there are too many groups to choose from, a rare fracture may become obscure making it difficult to evaluate different characteristics and treatment options. Classifications are useful and should be employed, but both classification and diagnostic method used for the process must be improved if they are to be worth the time and effort involved.

\section{How should we evaluate results after treatment of injuries to the wrist?}

To investigate outcome in both paper I and III we mainly used a patient-reported outcome measure (PROM), the PRWE questionnaire. Traditionally, focus has been on objective measures such as grip strength, range of motion, and clinical examinations such as stability. We believe that PROMs provide an important dimension when assessing the result of treatment and how it affects the patient. Individuals have different requirements when it comes to mobility or grip strength, but objective measurements do not necessarily reflect the patient's perception of satisfactory wrist function. Use of the PRWE questionnaire provides us with such subjective information. 
PROMs describe how the patients perceive their condition/injury after treatment whereas PREMs (patient-reported experience measures) describe the patient's perception of the health care system; process, structure and function. In this thesis no PREM was included, but to gain a complete picture of the patient's opinion, and thereby improving treatments and processes that focus on the patient, it would probably be of value to include both PROMs and PREMs in future studies. A baseline value is essential when evaluating the results of a particular treatment. Paper I was a retrospective study, and since the procedures studied were performed before PRWE came into being, we have no baseline data. A prospective study is necessary to demonstrate the true value of TFCC repair i.e., where objective measurements are made and PRWE answered both before and after surgery. When using PROMs to evaluate the treatment of an acute injury, as in paper III, comparison with normative data is valuable. Normative data are available for PRWE, showing a median score of 0 (Mulders, Kleipool et al. 2018). This means that our study showed that there is residual disability after distal ulna fracture management, and that current treatments do not return wrist function to preinjury levels. 


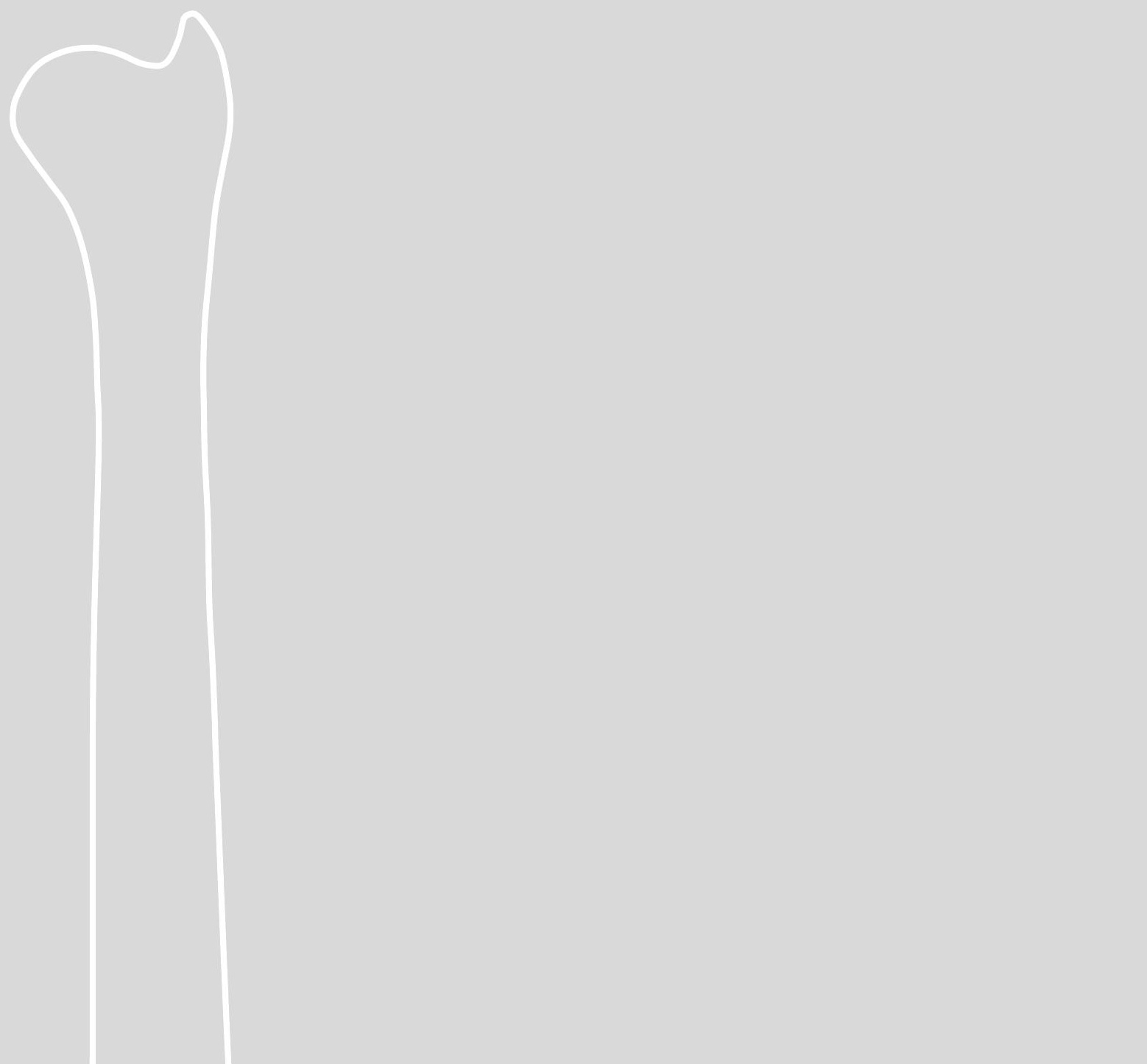




\section{Conclusions}

Before deciding on the right treatment for ulnar-sided wrist pain, we must first diagnose the cause correctly starting with adequate imaging studies. Arthroscopy is, in experienced hands, to this date the best way to diagnose a ligament injury when patient history and clinical examination has raised suspicion. It is also valuable when multiple injuries are present, when choosing treatment, when identifying associated injuries and when predicting outcome. If no other injuries are present, repair of a foveal TFCC tear usually leads to good results with better wrist function and reduction in pain. Plain radiography is not always enough to accurately diagnose a fracture, and give little information about fractures of the distal ulna. Not knowing exactly what type of fracture one is dealing with may well affect the results of treatment. With the use of CT and CBCT, more information about fracture patterns can now be achieved making classification more accurate. This will also enable us to design a better classification system, and for the classification to be useful it needs to be relevant in the clinical setting. An improved classification of distal ulna fractures will help with this and guide in choosing treatment by developing a treatment algorithm. Distal ulna fracture is not common but its importance should be recognised and given the same amount of attention as its larger cousin, the radius. Many distal ulna fractures seem not to need surgical treatment. Extra-articular transverse fractures, the most common type of distal ulna fracture apart from styloid fractures, will heal well as long as the radius provides stability and alignment. I hope this thesis will contribute to a better understanding of distal ulna fractures, and thereby be beneficial for this group of patients. 


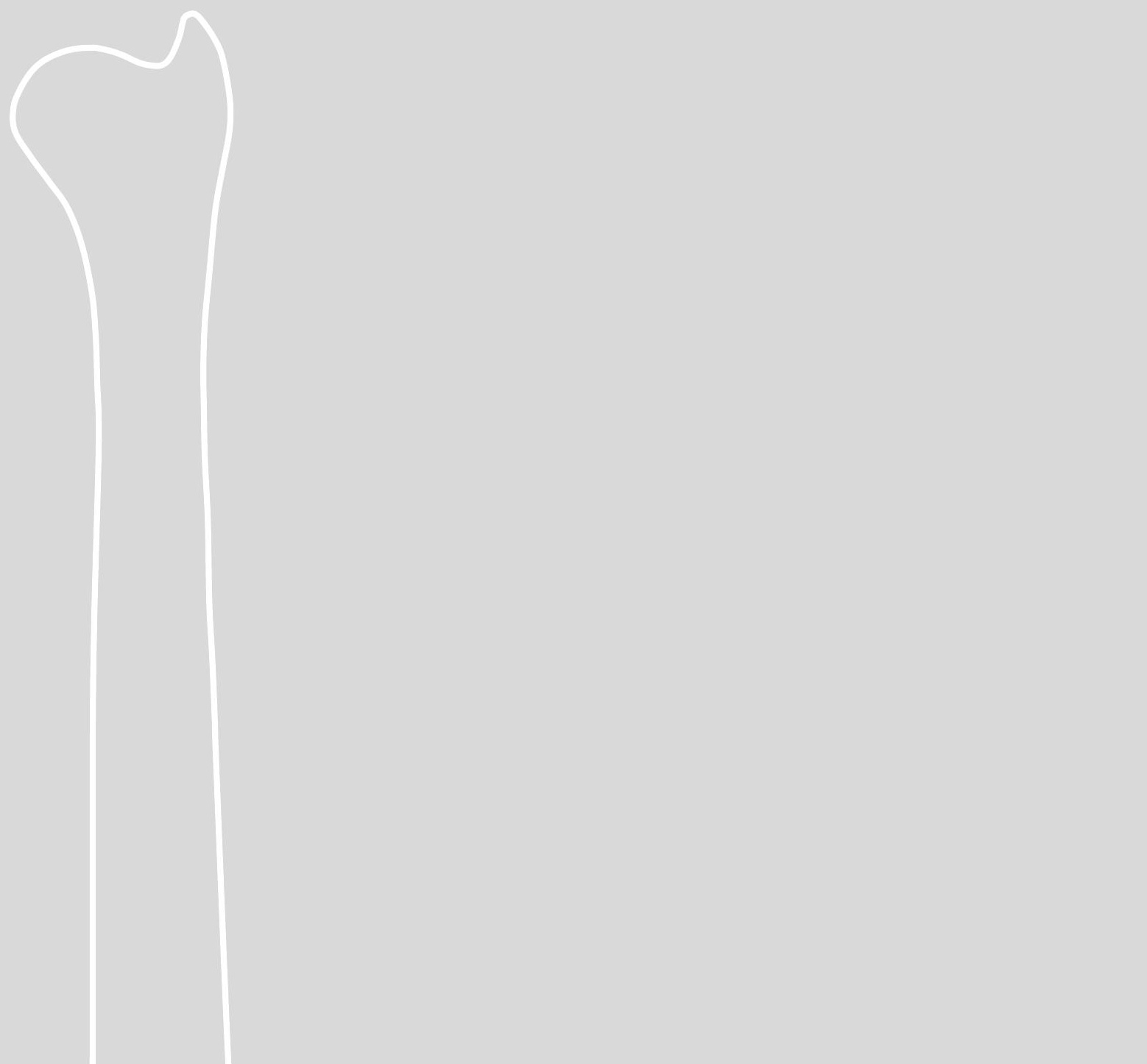




\section{Future research}

A prospective study is the best way to identify those distal ulna fractures that are likely to benefit from surgical treatment with internal fixation. Until now, most studies on distal ulna fractures have been retrospective. I believe that, with access to a better distal ulna fracture classification system, we should be able to improve evaluation and comparison of various methods of fixation prospectively. However, distal ulna fractures are relatively uncommon, and such studies are almost impossible to carry out at one or even several units, so large multi-centre or prospective register studies will be necessary to achieve significant results. Furthermore, classification itself divides fractures into smaller subgroups making it even harder to find significant differences. In this respect, the Swedish National Fracture Register may prove helpful in providing a bigger cohort of distal ulna fractures. When evaluating a new fracture classification, it's important to show that it is better than its predecessors. Studies comparing the reliability and reproducibility of a new classification are therefore necessary. With better imaging modalities classification will hopefully be more accurate and make a treatment algorithm for ulna fractures possible. 


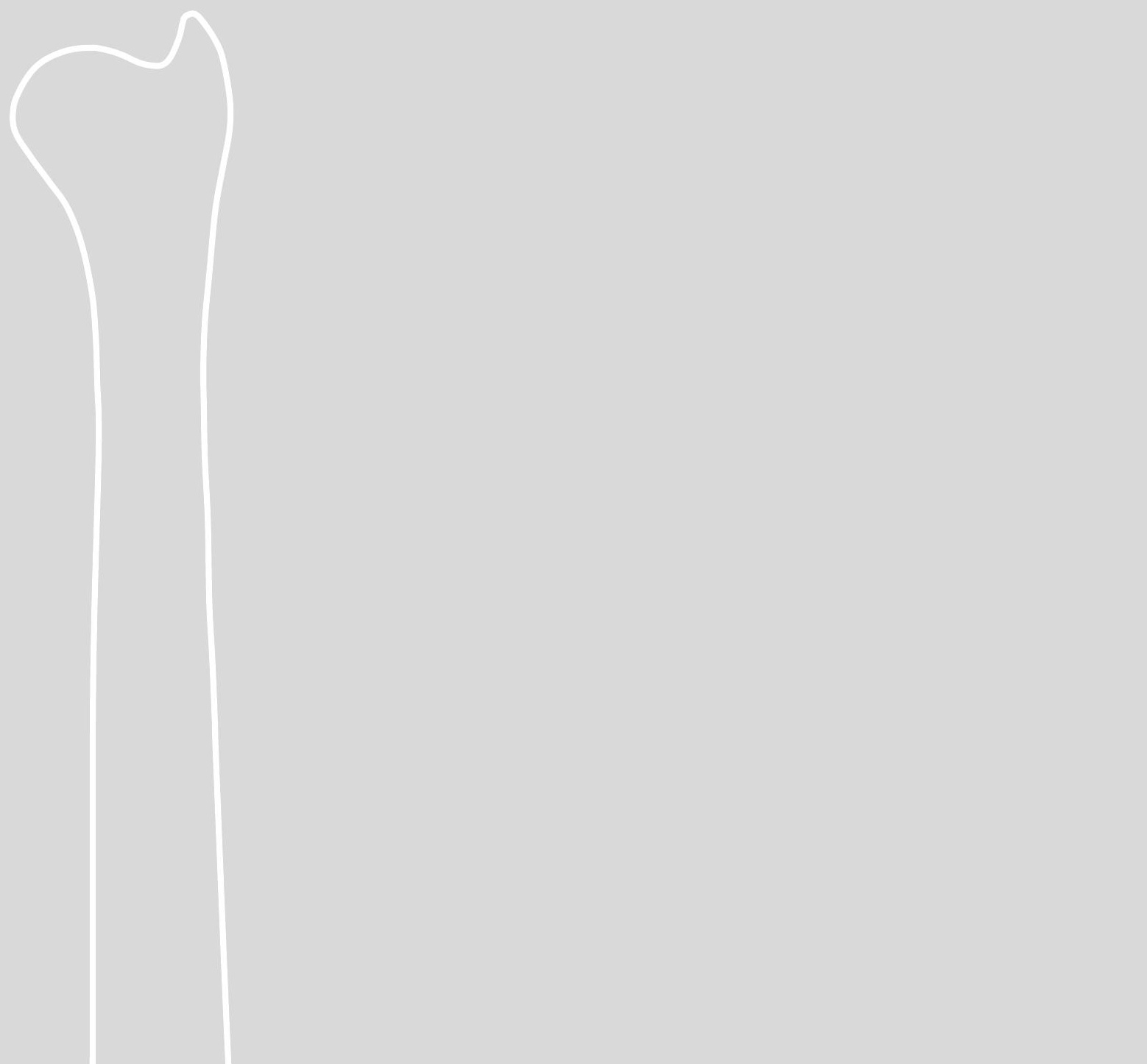




\section{Acknowledgements}

\section{Professor Lars Adolfsson}

For inviting me to a truly interesting research field, making research more fun than I ever thought before. For always finding the time to read what I've written and answering every stupid question I might have had. Thanks for being a great mentor and inspiration!

\section{Professor Simon Farnebo}

For all the difficult questions, making me think a step further. For all the interesting discussions and inspiring me to read more, improve and learn new things. For all the support and encouragement.

\section{Tomas Persson}

For gladly accepting to participate in all radiological aspects of my research, investing time and offering valuable opinions. Also a big thank you for the help with the cover picture of this book.

\section{Göran Nylander}

For opening my eyes to Hand Surgery and making it the only specialty I could consider!

\section{Carin Rubensson}

For supporting me in every aspect, from my first steps towards being a Hand Surgeon to every part of my research and finally finishing this thesis. You're the best colleague one could ever have.

\section{Johan Zötterman}

For the guidance in how to create nice looking pictures, making the appearance of this thesis better than I ever hoped.

\section{Peter Cox}

For helping me make this thesis readable.

\section{Lars Valter and Mats Fredriksson}

For all the statistical advice and guidance.

\section{All colleagues at the Department of Hand Surgery, Plastic Surgery and Burns}

For creating an open climate with room for discussion and learning from each other, and most importantly for being good friends. 


\section{Agneta Kåredal}

For all the support and always believing in me. For spoiling me and making sure I sometimes took a break.

\section{Jan Kåredal}

For all the interesting questions and discussions. For helping me with every radiological aspect of my research and for the support whenever times were hard. Thanks for always being there!

\section{Inger Kåredal}

For keeping track through the classifications and speeding up the process. For all the support and care.

\section{Zachary}

For being my greatest supporter and husband, making me laugh and saving me from being a total square.

\section{Elise and Dorian}

For managing to avoid pulling down and breaking my computer, despite the urge to skip rope with the cord, while the research computer has lived on our kitchen table. 


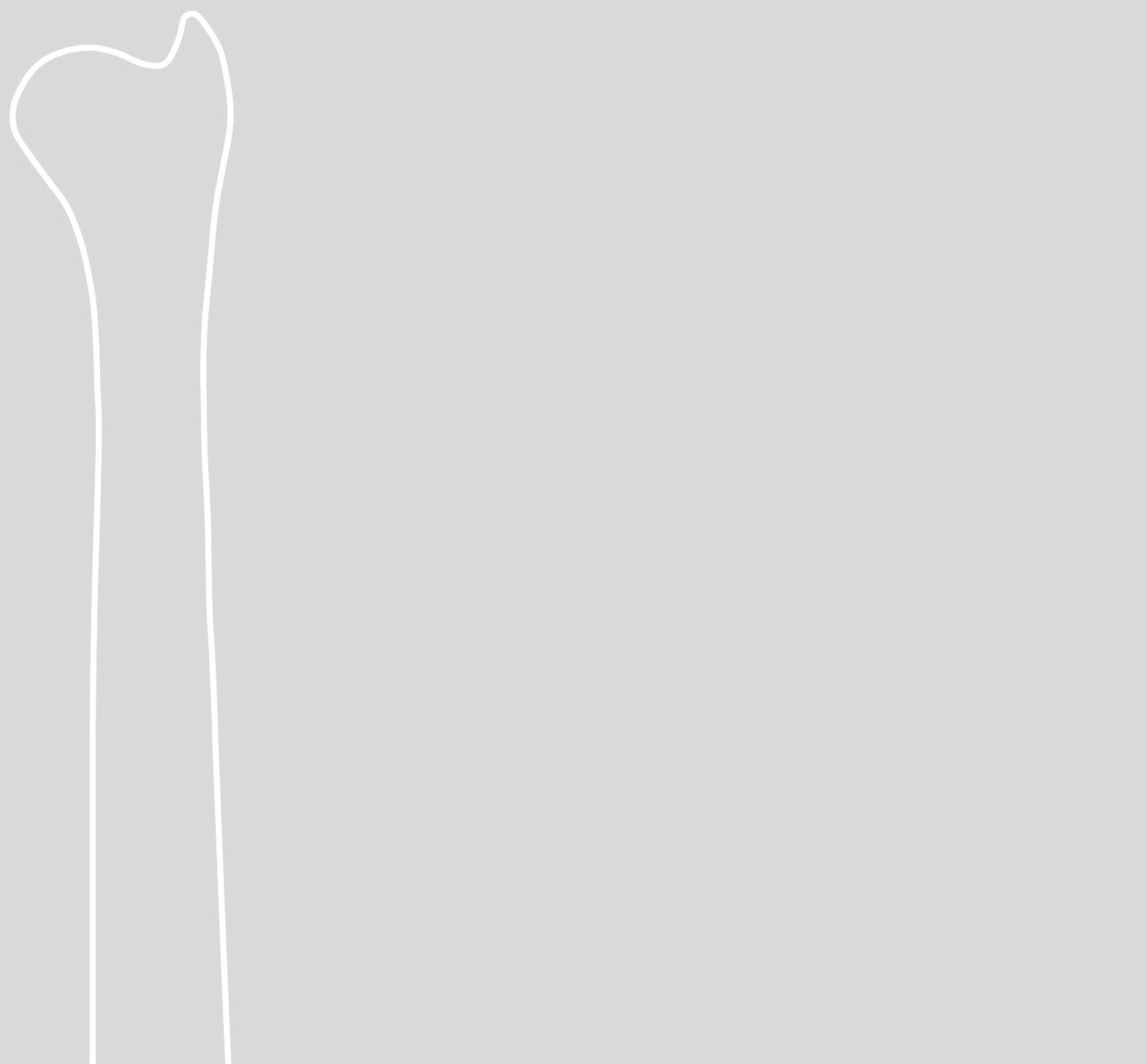




\section{References}

Adolfsson, L. (1994). "Arthroscopic diagnosis of ligament lesions of the wrist." J Hand Surg Br 19(4): 505-512.

af Ekenstam, F. and C. G. Hagert (1985). "Anatomical studies on the geometry and stability of the distal radio ulnar joint." Scand J Plast Reconstr Surg 19(1): 17-25.

Anderson, M. L., A. N. Larson, S. L. Moran, W. P. Cooney, K. K. Amrami and R. A. Berger (2008). "Clinical comparison of arthroscopic versus open repair of triangular fibrocartilage complex tears." J Hand Surg Am 33(5): 675-682.

Atzei, A. and R. Luchetti (2011). "Foveal TFCC tear classification and treatment." Clin 27(3): 263-272.

Atzei, A., R. Luchetti, D. Carletti, L. L. Marcovici, L. Cazzoletti and S. Barbon (2021). "The Hook Test Is More Accurate Than the Trampoline Test to Detect Foveal Tears of the Triangular Fibrocartilage Complex of the Wrist." Arthroscopy 37(6): 1800-1807.

Berger, R. A. (2001). "The anatomy of the ligaments of the wrist and distal radioulnar joints." Clin Orthop Relat Res(383): 32-40.

Biyani, A., A. J. Simison and L. Klenerman (1995). "Fractures of the distal radius and ulna." J Hand Surg Br 20(3): 357-364.

Boretto, J. G., E. E. Zaidenberg, G. L. Gallucci, A. Sarme and P. De Carli (2019). "Comparative Study of Internal Fixation of the Ulna and Distal Ulna Resection in Patients Older Than 70 Years With Distal Radius and Distal Metaphyseal Ulna Fractures." Hand (N Y) 14(4): 540-546.

Brogan, D. M., R. A. Berger and S. Kakar (2019). "Ulnar-Sided Wrist Pain: A Critical Analysis Review." JBJS Rev 7(5): e1.

Brogren, E., M. Hofer, M. Petranek, P. Wagner, L. B. Dahlin and I. Atroshi (2011). "Relationship between distal radius fracture malunion and arm-related disability: a prospective population-based cohort study with 1-year follow-up." BMC Musculoskelet Disord 12: 9.

Brogren, E., M. Petranek and I. Atroshi (2007). "Incidence and characteristics of distal radius fractures in a southern Swedish region." BMC Musculoskelet Disord 8: 48.

Bruno, F., F. Arrigoni, P. Palumbo, R. Natella, N. Maggialetti, A. Reginelli, A. Splendiani, E. Di Cesare, A. Bazzocchi, G. Guglielmi, C. Masciocchi and A. Barile (2019). "The Acutely Injured Wrist." Radiol Clin North Am 57(5): 943-955.

Burnier, M., G. Herzberg, R. Luchetti, F. Del Pinal and S. Kakar (2021). "Dry Wrist Arthroscopy for Ulnar-Sided Wrist Disorders." J Hand Surg Am 46(2): 133-141. 
Cha, S. M., H. D. Shin, K. C. Kim and E. Park (2012). "Treatment of unstable distal ulna fractures associated with distal radius fractures in patients 65 years and older." J Hand Surg Am 37(12): 2481-2487.

Changulani, M., U. Okonkwo, T. Keswani and Y. Kalairajah (2008). "Outcome evaluation measures for wrist and hand: which one to choose?" Int Orthop 32(1): 1-6.

Cherian, B. S., A. K. Bhat, K. V. Rajagopal, S. B. Maddukuri, D. Paul and N. J. Mathai (2020). "Comparison of MRI \& direct MR arthrography with arthroscopy in diagnosing ligament injuries of wrist." J Orthop 19: 203-207.

Court-Brown, C. M. and B. Caesar (2006). "Epidemiology of adult fractures: A review." Injury 37(8): 691-697.

Dacombe, P. J., R. Amirfeyz and T. Davis (2016). "Patient-Reported Outcome Measures for Hand and Wrist Trauma: Is There Sufficient Evidence of Reliability, Validity, and Responsiveness?" Hand (N Y) 11(1): 11-21.

del Pinal, F., F. J. Garcia-Bernal, D. Pisani, J. Regalado, H. Ayala and A. Studer (2007). "Dry arthroscopy of the wrist: surgical technique." J Hand Surg Am 32(1): 119-123.

del Pinal, F. M., C.; Luchetti, R. (2010). Arthroscopic Management of Distal Radius Fractures. Berlin Heidelberg, Springer.

Estrella, E. P., L. K. Hung, P. C. Ho and W. L. Tse (2007). "Arthroscopic repair of triangular fibrocartilage complex tears." Arthroscopy 23(7): 729-737, 737 e721.

Ferreira, L. M., G. S. Greeley, J. A. Johnson and G. J. King (2015). "Load transfer at the distal ulna following simulated distal radius fracture malalignment." J Hand Surg Am 40(2): 217-223.

Flinkkila, T., K. Sirnio, M. Hippi, S. Hartonen, R. Ruuhela, P. Ohtonen, P. Hyvonen and J. Leppilahti (2011). "Epidemiology and seasonal variation of distal radius fractures in Oulu, Finland." Osteoporos Int 22(8): 2307-2312.

Forward, D. P., T. R. Lindau and D. S. Melsom (2007). "Intercarpal ligament injuries associated with fractures of the distal part of the radius." J Bone Joint Surg Am 89(11): 2334-2340.

Gibney, B., M. Smith, A. Moughty, E. C. Kavanagh, D. Hynes and P. J. MacMahon (2019). "Incorporating Cone-Beam CT Into the Diagnostic Algorithm for Suspected Radiocarpal Fractures: A New Standard of Care?" AJR Am J Roentgenol 213(5): 1117-1123.

Hagert, E. and C. G. Hagert (2010). "Understanding stability of the distal radioulnar joint through an understanding of its anatomy." Hand Clin 26(4): 459-466.

Han, S. H., I. T. Hong and W. H. Kim (2014). "LCP distal ulna plate fixation of irreducible or unstable distal ulna fractures associated with distal radius fracture." Eur J Orthop Surg Traumatol 24(8): 1407-1413. 
Handoll, H. H. and P. Pearce (2012). "Interventions for treating isolated diaphyseal fractures of the ulna in adults." Cochrane Database Syst Rev(6): CD000523.

Haugstvedt, J. R., R. A. Berger, T. Nakamura, P. Neale, L. Berglund and K. N. An (2006). "Relative contributions of the ulnar attachments of the triangular fibrocartilage complex to the dynamic stability of the distal radioulnar joint." J Hand Surg Am 31(3): 445-451.

Hermansdorfer, J. D. and W. B. Kleinman (1991). "Management of chronic peripheral tears of the triangular fibrocartilage complex." J Hand Surg Am 16(2): 340-346.

Hove LM, L. T., Holmer P (2014). Distal Radius Fractures. heidelberg, New York, dordrecht, London, Springer.

Huang, J. I. and D. P. Hanel (2012). "Anatomy and biomechanics of the distal radioulnar joint." Hand Clin 28(2): 157-163.

Kakar, S. and M. Garcia-Elias (2016). "The "Four-Leaf Clover" Treatment Algorithm: A Practical Approach to Manage Disorders of the Distal Radioulnar Joint." J Hand Surg Am 41(4): 551-564.

Katt, B., D. Seigerman, K. Lutsky and P. Beredjiklian (2020). "Distal Radius Malunion." J Hand Surg Am 45(5): 433-442.

Kihara, H., W. H. Short, F. W. Werner, M. D. Fortino and A. K. Palmer (1995). "The stabilizing mechanism of the distal radioulnar joint during pronation and supination." $\underline{J}$ Hand Surg Am 20(6): 930-936.

Kijima, Y. and S. F. Viegas (2009). "Wrist anatomy and biomechanics." J Hand Surg Am 34(8): 1555-1563.

Kim, J. K., J. O. Kim and Y. D. Koh (2016). "Management of Distal Ulnar Fracture Combined with Distal Radius Fracture." J Hand Surg Asian Pac Vol 21(2): 155-160.

Kim, J. K. and E. S. Park (2013). "Comparative responsiveness and minimal clinically important differences for idiopathic ulnar impaction syndrome." Clin Orthop Relat Res 471(5): 1406-1411.

Kramer, S. B., C. A. Selles, D. Bakker and N. W. L. Schep (2021). "Comparison of extraarticular radiographic parameters of distal radius fractures on plain radiographs and $\mathrm{CT}$ scans." J Hand Surg Eur Vol: 17531934211021042.

Kvernmo, H. D. (2014). Associated Fractures of the Distal Ulna. Berlin Heidelberg, Springer.

Lawler, E. and B. D. Adams (2007). "Reconstruction for DRUJ instability." Hand (N Y) 2(3): 123-126.

Liang, B., J. M. Lai, A. Murugan, K. G. Chee, S. Sechachalam and T. L. Foo (2015). "Proposed Guidelines for Treatment of Concomitant Distal Radius and Distal Ulna Fractures." Hand Surg 20(3): 396-401. 
Lindau, T., C. Adlercreutz and P. Aspenberg (2000). "Peripheral tears of the triangular fibrocartilage complex cause distal radioulnar joint instability after distal radial fractures." J Hand Surg Am 25(3): 464-468.

Lindau, T., M. Arner and L. Hagberg (1997). "Intraarticular lesions in distal fractures of the radius in young adults. A descriptive arthroscopic study in 50 patients." $\mathrm{J}$ Hand Surg Br 22(5): 638-643.

Lindau, T., L. Hagberg, C. Adlercreutz, K. Jonsson and P. Aspenberg (2000). "Distal radioulnar instability is an independent worsening factor in distal radial fractures." Clin Orthop Relat Res(376): 229-235.

Logan, A. J. and T. R. Lindau (2008). "The management of distal ulnar fractures in adults: a review of the literature and recommendations for treatment." Strategies Trauma Limb Reconstr 3(2): 49-56.

Luchetti, R., A. Atzei, R. Cozzolino, T. Fairplay and N. Badur (2014). "Comparison between open and arthroscopic-assisted foveal triangular fibrocartilage complex repair for post-traumatic distal radio-ulnar joint instability." J Hand Surg Eur Vol 39(8): 845855.

MacDermid, J. C., R. S. Richards, A. Donner, N. Bellamy and J. H. Roth (2000). "Responsiveness of the short form-36, disability of the arm, shoulder, and hand questionnaire, patient-rated wrist evaluation, and physical impairment measurements in evaluating recovery after a distal radius fracture." J Hand Surg Am 25(2): 330-340.

MacDermid, J. C., T. Turgeon, R. S. Richards, M. Beadle and J. H. Roth (1998). "Patient rating of wrist pain and disability: a reliable and valid measurement tool." J Orthop Trauma 12(8): 577-586.

Mathoulin, C. (2015). Wrist Arthroscopy Techniques. Stuttgart, New York, Delhi, Rio de Janeiro, Thieme.

McPhail, S. M., K. S. Bagraith, M. Schippers, P. J. Wells and A. Hatton (2012). "Use of Condition-Specific Patient-Reported Outcome Measures in Clinical Trials among Patients with Wrist Osteoarthritis: A Systematic Review." Adv Orthop 2012: 273421.

Meinberg, E. G., J. Agel, C. S. Roberts, M. D. Karam and J. F. Kellam (2018). "Fracture and Dislocation Classification Compendium-2018." J Orthop Trauma 32 Suppl 1: S1-S170.

Mellstrand Navarro, C., S. Ponzer, H. Tornkvist, L. Ahrengart and G. Bergstrom (2011). "Measuring outcome after wrist injury: translation and validation of the Swedish version of the patient-rated wrist evaluation (PRWE-Swe)." BMC Musculoskelet Disord 12: 171.

Mikic, Z. D. (1995). "Treatment of acute injuries of the triangular fibrocartilage complex associated with distal radioulnar joint instability." J Hand Surg Am 20(2): 319-323.

Mrkonjic, A., M. Geijer, T. Lindau and M. Tagil (2012). "The natural course of traumatic triangular fibrocartilage complex tears in distal radial fractures: a 13-15 year follow-up of arthroscopically diagnosed but untreated injuries." J Hand Surg Am 37(8): 1555-1560. 
Mulders, M. A., A. Bentohami, M. S. Beerekamp, J. Vallinga, J. C. Goslings and N. W. Schep (2019). "Demographics, fracture patterns and treatment strategies following wrist trauma." Acta Orthop Belg 85(2): 234-239.

Mulders, M. A. M., S. C. Kleipool, S. A. Dingemans, P. V. van Eerten, T. Schepers, J. C. Goslings and N. W. L. Schep (2018). "Normative data for the Patient-Rated Wrist Evaluation questionnaire." J Hand Ther 31(3): 287-294.

Müller M.E., K. P., Nazarian S., Schatzker J. (1990). Radius/Ulna = 2. In: The Comprehensive Classification of Fractures of Long Bones. Berlin, Heidelberg, Springer.

Namba, J., T. Fujiwara, T. Murase, T. Kyo, I. Satoh and T. Tsuda (2009). "Intra-articular distal ulnar fractures associated with distal radial fractures in older adults: early experience in fixation of the radius and leaving the ulna unfixed." J Hand Surg Eur Vol 34(5): 592-597.

Noda, K., A. Goto, T. Murase, K. Sugamoto, H. Yoshikawa and H. Moritomo (2009). "Interosseous membrane of the forearm: an anatomical study of ligament attachment locations." J Hand Surg Am 34(3): 415-422.

Nypaver, C. and D. J. Bozentka (2021). "Distal Radius Fracture and the Distal Radioulnar Joint." Hand Clin 37(2): 293-307.

Omokawa, S., T. Gumpangseth, P. Komutrattananont, C. Inchai and P. Mahakkanukrauh (2021). "Anatomical Study of Stabilizing Structures of the Extensor Carpi Ulnaris Tendon Around the Wrist." J Hand Surg Am.

Ozkan, S., S. F. Fischerauer, T. J. M. Kootstra, F. Claessen and D. Ring (2018). "UInar Neck Fractures Associated with Distal Radius Fractures." J Wrist Surg 7(1): 71-76.

Pallaver, A. and P. Honigmann (2019). "The Role of Cone-Beam Computed Tomography (CBCT) Scan for Detection and Follow-Up of Traumatic Wrist Pathologies." J Hand Surg Am 44(12): 1081-1087.

Palmer, A. K. (1989). "Triangular fibrocartilage complex lesions: a classification." J Hand Surg Am 14(4): 594-606.

Paneru, S. R., R. Rijal, B. P. Shrestha, P. Nepal, G. P. Khanal, N. K. Karn, M. P. Singh and P. Rai (2010). "Randomized controlled trial comparing above- and below-elbow plaster casts for distal forearm fractures in children." J Child Orthop 4(3): 233-237.

Prommersberger, K. J., T. Pillukat, M. Muhldorfer and J. van Schoonhoven (2012). "Malunion of the distal radius." Arch Orthop Trauma Surg 132(5): 693-702.

Richards, T. A. and D. N. Deal (2014). "Distal ulna fractures." J Hand Surg Am 39(2): 385391.

Riggenbach, M. D., B. P. Conrad, T. W. Wright and P. C. Dell (2013). "Distal oblique bundle reconstruction and distal radioulnar joint instability." J Wrist Surg 2(4): 330-336. 
Ring, D., L. P. McCarty, D. Campbell and J. B. Jupiter (2004). "Condylar blade plate fixation of unstable fractures of the distal ulna associated with fracture of the distal radius." J Hand Surg Am 29(1): 103-109.

Ruch, D. S., C. C. Yang and B. P. Smith (2003). "Results of acute arthroscopically repaired triangular fibrocartilage complex injuries associated with intra-articular distal radius fractures." Arthroscopy 19(5): 511-516.

Sachar, K. (2012). "Ulnar-sided wrist pain: evaluation and treatment of triangular fibrocartilage complex tears, ulnocarpal impaction syndrome, and lunotriquetral ligament tears." J Hand Surg Am 37(7): 1489-1500.

Sadineni, R. T., A. Pasumarthy, N. C. Bellapa and S. Velicheti (2015). "Imaging Patterns in $\mathrm{MRI}$ in Recent Bone Injuries Following Negative or Inconclusive Plain Radiographs." J Clin Diagn Res 9(10): TC10-13.

Sato, K., K. Murakami, Y. Mimata, N. Numata, H. Shiraishi and M. Doita (2018). "Conservative treatment of distal ulna metaphyseal fractures associated with distal radius fractures in elderly people." Orthop Traumatol Surg Res 104(7): 1101-1105.

Scheer, J. H. and L. E. Adolfsson (2011). "Pathomechanisms of ulnar ligament lesions of the wrist in a cadaveric distal radius fracture model." Acta Orthop 82(3): 360-364.

Scheer, J. H. and L. E. Adolfsson (2012). "Patterns of triangular fibrocartilage complex (TFCC) injury associated with severely dorsally displaced extra-articular distal radius fractures." Injury 43(6): 926-932.

Schmitt, J. S. and R. P. Di Fabio (2004). "Reliable change and minimum important difference (MID) proportions facilitated group responsiveness comparisons using individual threshold criteria." J Clin Epidemiol 57(10): 1008-1018.

Schuind, F., K. N. An, L. Berglund, R. Rey, W. P. Cooney, 3rd, R. L. Linscheid and E. Y. Chao (1991). "The distal radioulnar ligaments: a biomechanical study." J Hand Surg Am 16(6): 1106-1114.

Selles, C. A., P. N. d'Ailly and N. W. L. Schep (2020). "Patient-Reported Outcomes following Arthroscopic Triangular Fibrocartilage Complex Repair." J Wrist Surg 9(1): 5862.

Soreide, E., T. Husby and J. R. Haugstvedt (2017). "A long-term (20 years') follow-up after arthroscopically assisted repair of the TFCC." J Plast Surg Hand Surg 51(5): 296-300.

Sorensen, A. A., D. Howard, W. H. Tan, J. Ketchersid and R. P. Calfee (2013). "Minimal clinically important differences of 3 patient-rated outcomes instruments." J Hand Surg Am 38(4): 641-649.

Spies, C. K., M. Langer, L. P. Muller, J. Oppermann and F. Unglaub (2020). "Distal radioulnar joint instability: current concepts of treatment." Arch Orthop Trauma Surg 140(5): 639-650. 
Taleisnik, J. (1976). "The ligaments of the wrist." J Hand Surg Am 1(2): 110-118.

Tay, S. C., K. Tomita and R. A. Berger (2007). "The "ulnar fovea sign" for defining ulnar wrist pain: an analysis of sensitivity and specificity." J Hand Surg Am 32(4): 438-444.

Thalhammer, G., T. Haider, M. Lauffer and H. G. Tunnerhoff (2021). "Mid- and LongTerm Outcome After Arthroscopically Assisted Transosseous Triangular Fibrocartilage Complex Refixation-Good to Excellent Results in Spite of Some Loss of Stability of the Distal Radioulnar Joint." Arthroscopy 37(5): 1458-1466.

Tolat, A. R., J. K. Stanley and I. A. Trail (1996). "A cadaveric study of the anatomy and stability of the distal radioulnar joint in the coronal and transverse planes." $\underline{\mathrm{J} \text { Hand Surg }}$ Br 21(5): 587-594.

Treiser, M. D., K. Crawford and M. L. Iorio (2018). "TFCC Injuries: Meta-Analysis and Comparison of Diagnostic Imaging Modalities." J Wrist Surg 7(3): 267-272.

Varitimidis, S. E., G. K. Basdekis, Z. H. Dailiana, M. E. Hantes, K. Bargiotas and K. Malizos (2008). "Treatment of intra-articular fractures of the distal radius: fluoroscopic or arthroscopic reduction?" J Bone Joint Surg Br 90(6): 778-785.

Vezeridis, P. S., H. Yoshioka, R. Han and P. Blazar (2010). "Ulnar-sided wrist pain. Part I: anatomy and physical examination." Skeletal Radiol 39(8): 733-745.

Walenkamp, M. M., R. J. de Muinck Keizer, J. C. Goslings, L. M. Vos, M. P. Rosenwasser and N. W. Schep (2015). "The Minimum Clinically Important Difference of the Patientrated Wrist Evaluation Score for Patients With Distal Radius Fractures." Clin Orthop Relat Res 473(10): 3235-3241.

Watanabe, A., F. Souza, P. S. Vezeridis, P. Blazar and H. Yoshioka (2010). "Ulnar-sided wrist pain. II. Clinical imaging and treatment." Skeletal Radiol 39(9): 837-857.

Watanabe, M. (1972). "[Present status and future of arthroscopy]." Geka Chiryo 26(1): 73-77.

Whipple, T. L., J. J. Marotta and J. H. Powell, 3rd (1986). "Techniques of wrist arthroscopy." Arthroscopy 2(4): 244-252.

Wilcke, M. K., H. Hammarberg and P. Y. Adolphson (2013). "Epidemiology and changed surgical treatment methods for fractures of the distal radius: a registry analysis of 42,583 patients in Stockholm County, Sweden, 2004-2010." Acta Orthop 84(3): 292-296.

Wilcke, M. T., H. Abbaszadegan and P. Y. Adolphson (2009). "Evaluation of a Swedish version of the patient-rated wrist evaluation outcome questionnaire: good responsiveness, validity, and reliability, in 99 patients recovering from a fracture of the distal radius." Scand J Plast Reconstr Surg Hand Surg 43(2): 94-101.

Williams, E. A. and J. B. Friedrich (2011). "Retrospective analysis demonstrates no advantage to operative management of distal ulna fractures." Hand (N Y) 6(4): 378-383. 


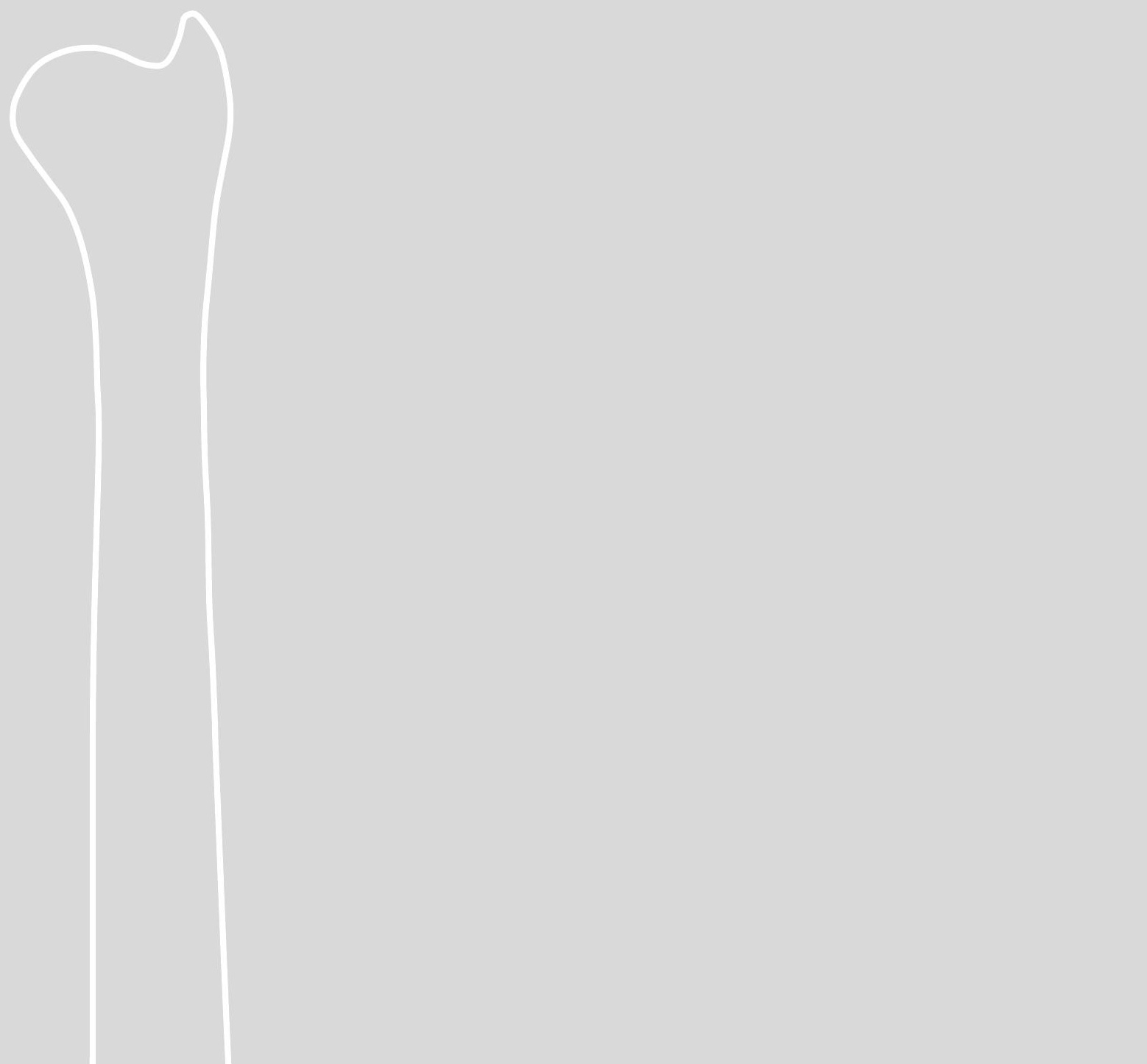


Papers 


\section{Papers}

The papers associated with this thesis have been removed for copyright reasons. For more details about these see:

https://doi.org/10.3384/9789179291730 


\title{
FACULTY OF MEDICINE AND HEALTH SCIENCES
}

\author{
Linköping University Medical Dissertation No. 1797, 2022 \\ Department of Biomedical and Clinical Sciences \\ Linköping University \\ SE-581 83 Linköping, Sweden
}

www.liu.se

\begin{tabular}{|c|c|c|c|c|}
\hline Paper & Aims & Method & Patients & Results and conclusions \\
\hline I & $\begin{array}{l}\text { Investigate functional } \\
\text { results and rate of } \\
\text { osteoarthritis [OA] } \\
20 \text { years after a } \\
\text { TFCC-repair. }\end{array}$ & $\begin{array}{l}\text { Long-term } \\
\text { follow up. PROM. } \\
\text { Radiology }\end{array}$ & 47 patients & $\begin{array}{l}\text { Worse outcome was seen } \\
\text { in patients that required } \\
\text { additional surgery or who } \\
\text { developed OA. Less OA was } \\
\text { seen in patients who had an } \\
\text { arthroscopy. }\end{array}$ \\
\hline ॥ & $\begin{array}{l}\text { Investigate the } \\
\text { incidence of distal } \\
\text { ulna fractures in } \\
\text { adults, divided by } \\
\text { fracture classification } \\
\text { and chosen treatment. }\end{array}$ & $\begin{array}{l}\text { Epidemiological } \\
\text { study }\end{array}$ & 766 patients & $\begin{array}{l}\text { The incidence was } 74 / 100 \\
000 \text { person-years. Most } \\
\text { common was fractures of } \\
\text { the ulnar styoid, followed by } \\
\text { the ulnar neck. Excluding } \\
\text { the styloid fractures, a third } \\
\text { were treated operatively. }\end{array}$ \\
\hline III & $\begin{array}{l}\text { Investigate the } \\
\text { results after distal } \\
\text { ulna fractures and if } \\
\text { fracture classification } \\
\text { could predict outcome. }\end{array}$ & $\begin{array}{l}\text { Retrospective. } \\
\text { PROM. Radiology }\end{array}$ & $\begin{array}{l}96 \text { patients } \\
\text { (97 fractures) }\end{array}$ & $\begin{array}{l}\text { Patient reported outcome } \\
\text { was better in extra-articular } \\
\text { transverse distal ulna } \\
\text { fractures when treated } \\
\text { non-operatively. Outcome } \\
\text { was not predicted by the } \\
\text { classification. }\end{array}$ \\
\hline IV & $\begin{array}{l}\text { Compare three } \\
\text { classification } \\
\text { systems of distal ulna } \\
\text { fractures. }\end{array}$ & $\begin{array}{l}\text { Comparative } \\
\text { analysis of } \\
\text { reliability and } \\
\text { reproducibility }\end{array}$ & $\begin{array}{l}96 \text { patients } \\
\text { (97 fractures) }\end{array}$ & $\begin{array}{l}\text { The inter-rater agreement } \\
\text { was fair to moderate and } \\
\text { the intra-rater agreement } \\
\text { moderate for all three } \\
\text { classification systems. Plain } \\
\text { radiographs were percieved } \\
\text { as insufficient. }\end{array}$ \\
\hline
\end{tabular}

